\title{
Application of Optical Remote Sensing in Rubber Plantations: A Systematic Review
}

\author{
Fathin Ayuni Azizan ${ }^{1,2, * \mathbb{D}}$, Adhitya Marendra Kiloes ${ }^{1} \mathbb{D}$, Ike Sari Astuti ${ }^{3}$ and Ammar Abdul Aziz ${ }^{1}$ (D) \\ 1 School of Agriculture and Food Science, The University of Queensland, Gatton, QLD 4343, Australia; \\ a.kiloes@uq.net.au (A.M.K.); a.abdulaziz@uq.edu.au (A.A.A.) \\ 2 Faculty of Chemical Engineering Technology, Universiti Malaysia Perlis, Perlis 02600, Malaysia \\ 3 Department of Geography, Universitas Negeri Malang, Jawa Timur 65145, Indonesia; ike.sari.fis@um.ac.id \\ * Correspondence: f.azizan@uq.net.au
}

\section{check for}

updates

Citation: Azizan, F.A.; Kiloes, A.M.; Astuti, I.S.; Abdul Aziz, A.

Application of Optical Remote

Sensing in Rubber Plantations: A

Systematic Review. Remote Sens. 2021,

13, 429. https://doi.org/10.3390/

rs13030429

Received: 9 December 2020

Accepted: 20 January 2021

Published: 26 January 202

Publisher's Note: MDPI stays neutral with regard to jurisdictional claims in published maps and institutional affiliations.

Copyright: (C) 2021 by the authors. Licensee MDPI, Basel, Switzerland. This article is an open access article distributed under the terms and conditions of the Creative Commons Attribution (CC BY) license (https:/ / creativecommons.org/licenses/by/ $4.0 /)$.

\begin{abstract}
Rubber (Hevea brasiliensis) is a tropical tree crop cultivated for the industrial production of latex. The trees are tall, perennial and long-lived, and are typically grown in plantations. In most rubber-producing countries, smallholders account for more than $85 \%$ of plantation area. Traditional practices mean that it can be difficult to monitor rubber plantations for management purposes. To overcome issues associated with monitoring traditional practices, remote sensing approaches have been successfully applied in this field. However, information on this is lacking. Therefore, this study aims to document the current status, history, development and prospects for remote sensing applications in rubber plantations by using the PRISMA framework. The review focuses on the application of optical remote sensing data in rubber. In this paper, we discuss the current role of remote sensing on specific subject areas, namely mapping, change detection, stand age estimation, carbon and biomass assessment, leaf area index (LAI) prediction and disease detection. In addition, we elaborate on the benefits gained and challenges faced while adapting this technology. These include the availability and free access to satellite imagery as the greatest benefit and the presence of clouds as one of the toughest challenges. Finally, we highlighted four potential areas where future work can be done: (1) Advancements in remote sensing data, (2) algorithm enhancements, (3) emerging processing platforms, and (4) application to less studied subject areas. This paper gives insight into strengthening the potential of remote sensing for delivering efficient and long-term services for rubber plantations.
\end{abstract}

Keywords: smallholders; natural rubber production; agroforestry; optical; remote sensing

\section{Introduction}

The rubber tree, or Hevea brasiliensis sp. is a major tree crop cultivated for natural rubber production. It is mainly grown in tropical areas and has an economic lifespan of 30 to 35 years [1]. It occupies more than 11 million ha of agricultural land globally. An approximately 9.2 million ha (78\%) of total rubber are planted in Southeast Asia, with about 3.67 million ha (31\%) in Indonesia and 3.23 million ha (27\%) in Thailand [2]. Natural rubber is important to the global economy, being used as a raw material for more than 40,000 industrial and non-industrial products [3]. More than $60 \%$ of global rubber production is consumed by the tire manufacturing industry [4]. The production of natural rubber in 2018 was recorded at 14.33 million tonnes [2]. The major producing countries are Thailand, Indonesia, Vietnam, India, China and Malaysia.

Rubber trees were cultivated in large estates over the last century, but rubber cultivation has gradually shifted to the smallholder sector [5]. While there are still large-scale economic concessions in countries like Brazil and Vietnam [6,7], it only accounts for a small fraction of the world's natural rubber production. Most Southeast Asian countries have shifted into smallholdings. In 2018, Southeast Asia contributes more than three-quarters of the world's natural rubber production [2]. 
Natural rubber production is vital for smallholder livelihoods because this sector dominates more than $75 \%$ of the world's natural rubber production $[6,7]$. There are a total of 13 million rubber smallholders around the world. The definition of rubber smallholders differs between countries based on the rubber land size: Malaysia $(<40.5 \mathrm{ha})$; Thailand ( $<40 \mathrm{ha}) ;$ Indonesia ( $<25 \mathrm{ha}) ;$ Laos ( $<25 \mathrm{ha}) ;$ India ( $<20 \mathrm{ha}) ;$ Sri Lanka $(<20 \mathrm{ha})$ and Myanmar ( $<8 \mathrm{ha}$ ) [7]. However, it is reported that a majority of the rubber smallholders have less than 4 ha [8,9]. The share of smallholding in rubber production is high in Malaysia, Thailand, Myanmar, India and Indonesia, ranging between $85 \%$ and $93 \%[7,10]$. Besides generally owning small plots, rubber smallholders implement poor agricultural practices and have limited access to financial resources [11,12]. Therefore, ensuring the sustainability of natural rubber production is crucial to world economic development.

In addition to the problems already faced by smallholders, rubber plantations are also exposed to other production challenges. These include pests and diseases [13-17]; poor agricultural management practices [18]; competition for land [16,19] and more recently, worldwide rapid expansion into unsuitable agricultural sites [20-24]. Effective plantation management and monitoring is therefore vital to ensure sustainable rubber production.

Monitoring plays an essential role in agricultural management and production [25-27]. Through effective and intensive monitoring, producers are able to identify corrective and preventive steps to optimise input while maximising production. Traditionally, rubber tree monitoring is time-consuming and labour-intensive. The collection of ground data relies heavily on conventional monitoring methods [28]. Current methods are incapable of offering accurate spatial and temporal information [29].

Remote sensing technology provides spatial and temporal information over large extents of an observed area [30-35]. It has played a vital role in mapping rubber trees at local and regional scales $[18,36-38]$ and has facilitated understanding of changes in spatial patterns of rubber plantations over time [39].

The focus on the application of remote sensing in rubber has never been more important, due to a recent global outbreak of rubber leaf disease [40]. This outbreak has resulted in significant production declines, severely impacting the livelihood of rubber smallholders. The present work aims to provide a comprehensive review of the application of optical remote sensing to rubber plantation monitoring.

\section{Methods}

The paper is divided into four sections. The first section explains the methodology used for conducting a systematic literature review. The second section provides an analysis of the selected documents. The third section discusses the approaches and methods used in the identified subject areas. The paper concludes by addressing the benefits, challenges and future potential of remote sensing monitoring of rubber plantations. The paper's findings will assist researchers, rubber organisations and policymakers in decision-making processes.

In this study, we adopt the standard systematic review guidelines as outlined in the Preferred Reporting Items for Systematic Reviews and Meta-Analyses (PRISMA) framework statement [41]. This is a well-known framework and it is widely used to generate systematic literature reviews [42]. It uses a clear and systematic method to identify, select and analyse relevant research documents from a set of formulated questions [43]. Unlike the narrative style of literature review, all available resources were used to search for related documents, thus minimising the potential for selection bias [44]. Data from the literature, that met the set criteria, was then extracted and synthesised.

\subsection{Inclusion and Exclusion Criteria}

The inclusion and exclusion criteria were outlined before the search was conducted. These criteria were used to eliminate papers during the eligibility screening process $[42,45,46]$. These criteria reflect the objective of the review. The use of these pre-specified criteria 
reduces errors, bias and inconsistency during decision-making while selecting related documents [47]. The set criteria are presented in Table 1.

Table 1. Inclusion and exclusion criteria set for the selection of documents.

\begin{tabular}{|c|c|}
\hline Inclusion Criteria & Exclusion Criteria \\
\hline $\begin{array}{l}\text { - Document discuss and focus on the } \\
\text { application of remote sensing in the } \\
\text { management and monitoring of } \\
\text { rubber plantations }\end{array}$ & $\begin{array}{l}\text { Discuss on other factors and aspects other } \\
\text { than the management and monitoring of } \\
\text { rubber plantation }\end{array}$ \\
\hline $\begin{array}{l}\text { Document used and analyse optical } \\
\text { remote sensing imagery (either solely } \\
\text { optical remote sensing data or in } \\
\text { combination with non-optical remote } \\
\text { sensing data) }\end{array}$ & $\begin{array}{l}\text { - General discussion which includes other } \\
\text { plantation or land cover }\end{array}$ \\
\hline - Full-text available & $\begin{array}{l}\text { - } \quad \text { Reviews, commentaries and } \\
\text { projection studies }\end{array}$ \\
\hline - Written in English language & - $\quad$ Published date beyond 2020 \\
\hline
\end{tabular}

\subsection{Search Methodology}

Articles were searched and identified from six bibliographic databases: Science Direct, Web of Science Core Collection, Scopus, ProQuest and Google Scholar. The primary keyword ("remote sensing") was paired with secondary keywords, such as "rubber plantation", using Boolean operators. This keyword set was used in all databases. The searches were conducted and updated up until December 2020. Table 2 shows details the database search terms and results.

Table 2. List of database with exact search term and results.

\begin{tabular}{|c|c|c|}
\hline Database & Terms & Results \\
\hline ScienceDirect & "rubber plantation" AND "remote sensing" & 209 \\
\hline Web of Science Core Collection & $\begin{array}{c}\text { TOPIC: (rubber plantation*) AND TOPIC: } \\
\left.\text { (remote sens }{ }^{*}\right)\end{array}$ & 82 \\
\hline Scopus & $\begin{array}{l}\text { TITLE-ABS-KEY (rubber AND plantation } \\
\text { AND remote AND sens }{ }^{*} \text { ) }\end{array}$ & 117 \\
\hline ProQuest & $\begin{array}{c}\left.\text { noft }^{1} \text { (rubber plantation }^{*}\right) \text { AND noft } \\
\left.\text { (remote sens }{ }^{*}\right)\end{array}$ & 47 \\
\hline Google Scholar & $\begin{array}{l}\text { with all of the words: "rubber plantation*" } \\
\text { with the exact phrase: "remote sens*" }\end{array}$ & 474 \\
\hline
\end{tabular}

All the identified articles from the search were filtered to remove duplicates, nonpeer-reviewed articles, and articles from unidentifiable sources. Next, the articles were screened by title and abstract to eliminate articles that did not meet the set criteria. The full text of the remaining articles were carefully reviewed to decide whether they met the inclusion criteria. In addition, we conducted cross-referencing to ensure no related articles were missed. Finally, details from the selected articles were extracted and compiled (see Appendix A). The details extracted included authors name, year, country of study area, sensor used, sensor resolution category, spatial extent, temporal scale, classification type, approach, reference data and accuracy method used.

\subsection{Additional Search}

To ensure that all of the relevant literature was included in this review, we conducted a manual search by adopting the snowballing method. It is a process of identifying literature 
from known references [47]. We adopted the backward snowballing technique by reviewing the selected articles' references to identify other relevant contributions in the area and including them in the review whenever the inclusion and exclusion criteria were met. This method was selected because it was considered best practice for systematic reviews [48].

\section{Descriptive Analysis}

Using the PRISMA framework (Figure 1), we identified 929 documents that were potentially relevant to this review. We removed 198 duplicated documents from this total. A further 631 documents were omitted due to irrelevant titles and abstracts. The search yielded a total of 100 documents for a full-text review. Of these, we excluded 45 documents, as they did not meet the inclusion criteria. We cross-referenced the remaining 55 documents and identified an additional 20 related documents. The final total of 74 documents met the set criteria for further synthesis in this review.

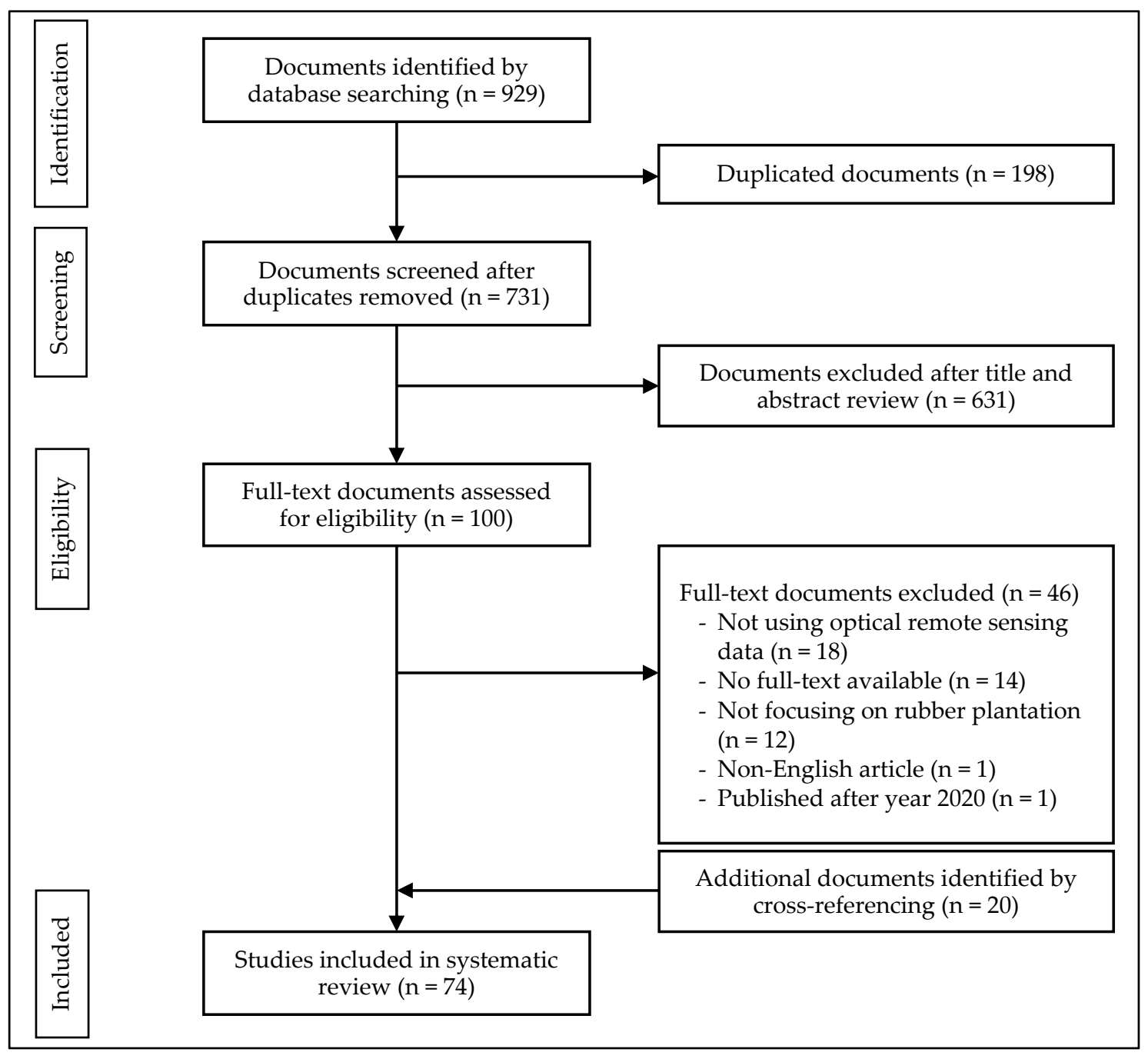

Figure 1. The literature selection process using Preferred Reporting Items for Systematic Reviews and Meta-Analyses (PRISMA) framework.

\subsection{Document Details}

Out of 74 documents reviewed, $58(78.4 \%)$ were peer-reviewed journal articles, 15 (20.3\%) were conference papers, and one $(1.3 \%)$ was a thesis. The earliest publication was in 2002 [49]. Figure 2 shows the distribution of the reviewed documents based on publication year. There were 13 documents published from 2002 to 2010. However, from 2011 onwards, 
61 documents were published. This represents a total of $82.4 \%$ of the documents identified in this literature review. This is most likely due to the availability of data from recently launched satellites and the Landsat open access policy [50]. The launching of Landsat 8 in 2014 and Sentinel-2 in 2015 may also have played a critical role in the high number of publications recorded in the following years. Overall, the published documents from 2002 to 2020 display an increasing trend.

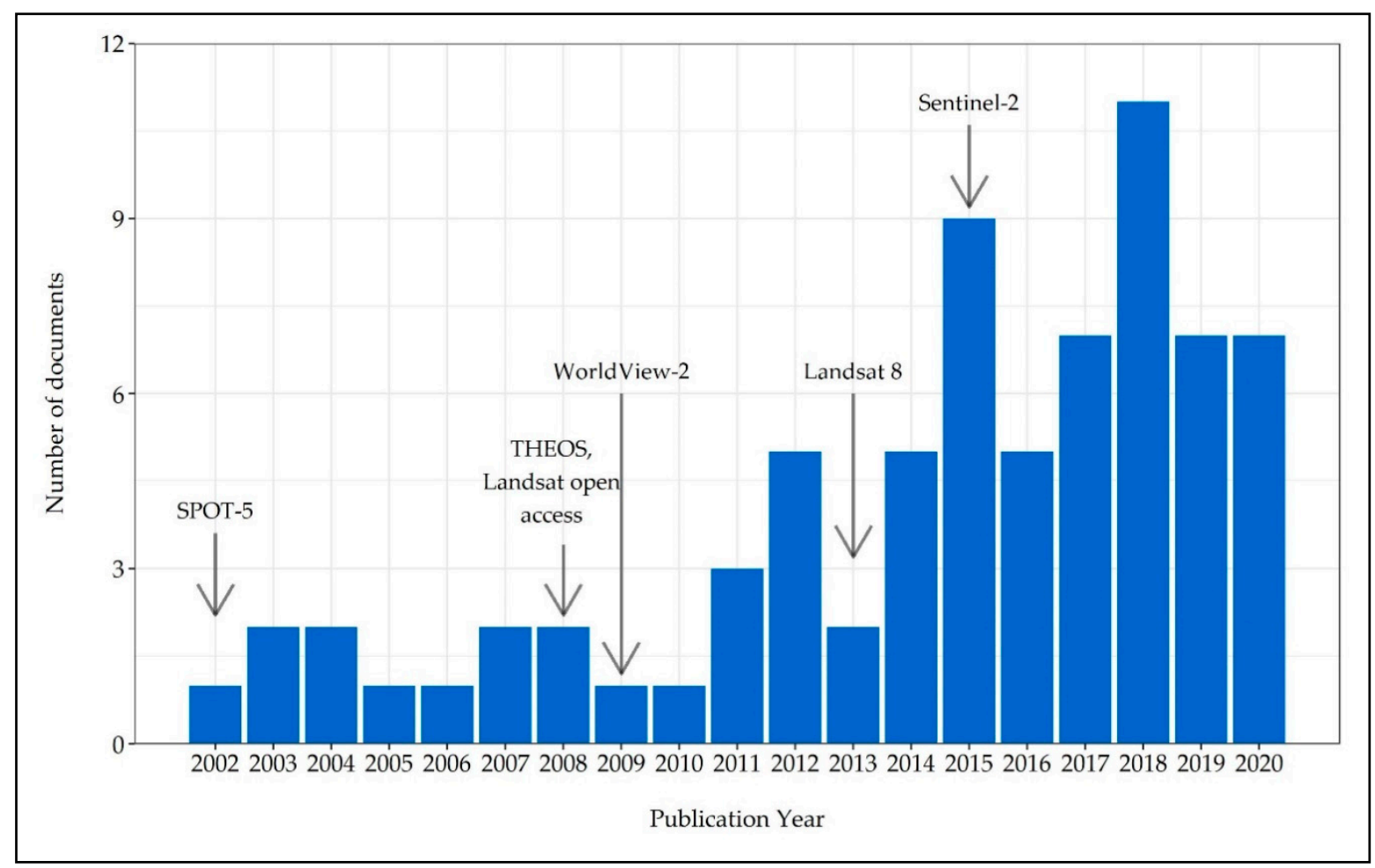

Figure 2. Distribution of the reviewed documents based on publication year (The arrows show important satellite launch years and the year Landsat implemented open access data).

\subsection{Study Setting}

The reviewed documents represented research conducted in two classes of spatial extent: Local and regional scale. Here we define local scale research as studies conducted in a single locality or country. On the other hand, regional-scale research implies a combination of cross-border studies [51]. All except six documents were conducted at a local scale. Of the six, five were small-scale cross-border research, while one was conducted at a larger scale in five countries in Southeast Asia. The lack of regional studies could be attributed to limited reference or ground data.

The local scale research was conducted in seven countries. The locations of these studies are presented in Figure 3. Out of 68 studies done at a local scale, more than onethird took place in China, making it the most dominant local scale study location. This may be due to the fact that China is a major rubber producer and the largest consumer of natural rubber [32,52]. This also reflects China's rapid planting area expansion [53]. It is also noted that most of the other study areas were located in Southeast Asia. Thailand and Malaysia had the highest number of studies at 14 and 13, respectively. Southeast Asia has the largest area planted to rubber and contributes up to $97 \%$ of total global natural rubber production [36]. Furthermore, it can be seen that the study areas lie between latitude $30^{\circ} \mathrm{N}$ to $30^{\circ} \mathrm{S}$, which has suitable agro-climatic conditions for rubber cultivation. 


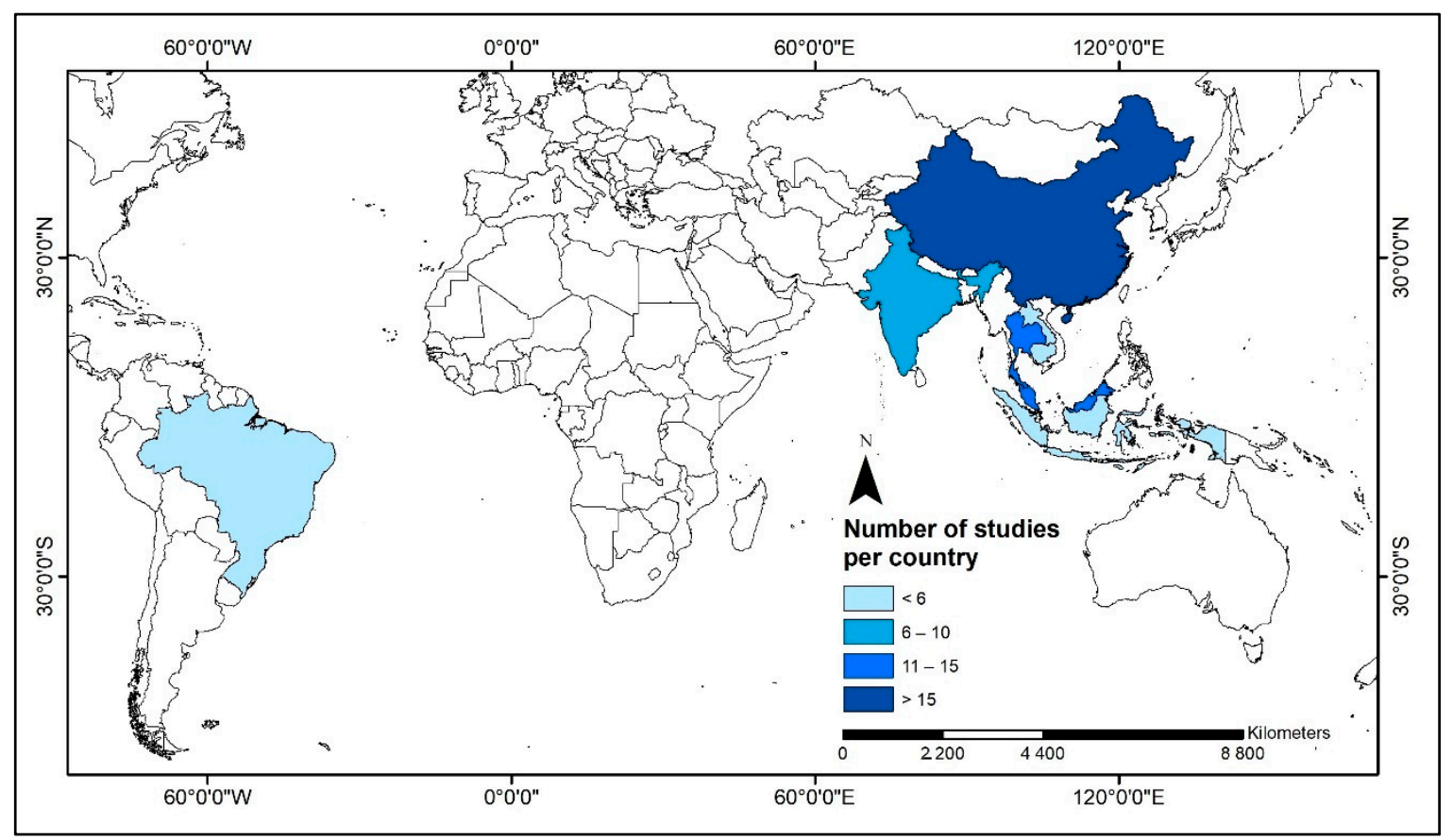

Figure 3. Map of the number of studies per country for local study setting.

\subsection{Remote Sensing Data}

Optical remote sensing data refers to imagery data from sensors that use solar illumination. It is also known as passive remote sensing. In this review, we evaluated the remote sensing sensors referred to in each of the selected documents. Figure 4 shows the distribution of documents that use single or multiple data sources, and the temporal scale analysed. A majority of the documents ( 40 out of 74 ) used a single data source to accomplish their study objective. However, documents published in later years were more likely to have used multiple optical data sources or a combination of data from active sensors like ALOS PALSAR. The combination of multiple optical satellite sensors can enhance the analysis and interpretation of remote sensing data.

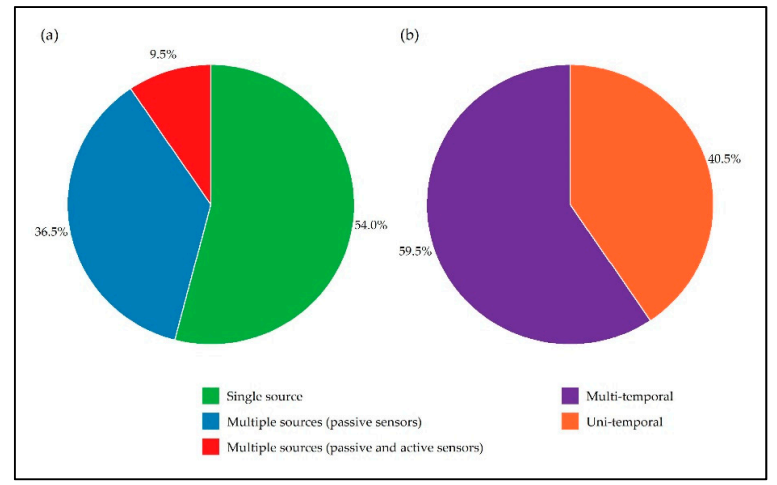

Figure 4. Distribution of documents based (a) types of sensors and (b) temporal scale analysed.

In assessing remote sensing resolutions, we discussed four types of resolutions: (1) Spatial; (2) spectral; (3) temporal; and (4) radiometric. These four resolutions reveal significant variability in details and quality. The spatial resolution of imagery used in all selected documents was found to range between $0.05 \mathrm{~m} \mathrm{[54]} \mathrm{and} 250 \mathrm{~m}$ [36]. Figure 5 lists the sensors used, along with their frequencies and respective spatial resolution classes. All except PALSAR and Sentinel-1 are optical sensors. When these data were tabulated into four classes of spatial resolution (low, medium, high and very high), the medium spatial resolution sensors were recorded as the most frequently used. Landsat TM (Landsat 4 and 
5) were the most broadly used sensors in this review, followed by Landsat 7, and Landsat 8 . This is because these data are freely available, in comparison to the large costs associated with high spatial resolution imagery.

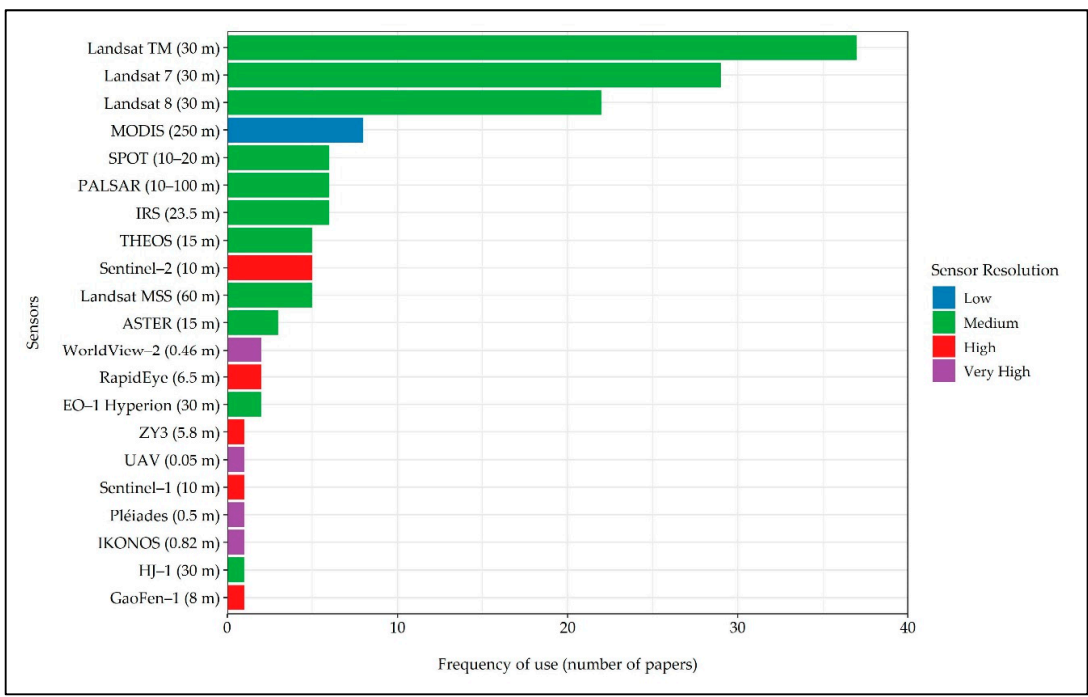

Figure 5. Distribution of used sensor types with its used frequency of use of data and respective spatial resolution classes from specific satellite missions.

Generally, the higher the spatial resolution of remote sensing data, the more detailed the information. However, the requirement for high spatial resolution in a rubber plantation setting may not be necessary, due to the size of the planting areas-although this does depend on the study objective. It should be noted that high spatial resolution data normally comes with lower spatial extent, therefore requiring more tiles to be combined together to encompass a large study area. This can be a costly image processing exercise.

Of the selected documents, only two reported the use of hyperspectral images from EO-1 Hyperion, which provided $10 \mathrm{~nm}$ bandwidth with spectral channels ranging from 0.357 to $2.576 \mu \mathrm{m}[55,56]$. The remaining research used multispectral images. The used of multispectral data were prevalent because all the relevant sensors provided a range of visible (RGB) and near-infrared (NIR) wavelengths. The NIR wavelengths were especially important because surface vegetation with higher chlorophyll levels reflects more nearinfrared energy. Furthermore, multispectral data are mostly free and data size is more manageable. In contrast, hyperspectral data are much larger and complex.

From the perspective of the radiometric resolution, the data ranges from as low as 6 bits, from Landsat MSS [57], to as high as 12 bits, from Landsat 8 [58]. The radiometric resolution for the satellites used in the majority of studies are Landsat MSS (6 bits), IRS-LISS III (7 bits), Landsat TM (8 bits), and Landsat ETM+ (9 bits). Interestingly, this also shows how newly-launched sensors with freely available data have improved resolution over time. The greater the bit depth, the better the measurement of small differences in reflected or emitted radiation captured.

Temporal resolution is an important criterion for multi-temporal studies. In general, a satellite with high revisit time provides the advantage of acquiring cloud-free images for multi-temporal analysis. The highest and lowest temporal resolution used in all 74 documents ranged from 1 day with MODIS [36] to 16 days with Landsat [59]. As shown in Figure 4,59.5\% (44 documents) of the selected documents used multi-temporal scale in their studies. Out of 44 documents, a majority (35 documents) used Landsat. More than $40 \%$ (20 out of 44 documents) of these studies were focused on rubber area expansion. These coincide with the rubber boom in the mid-2000s [60,61]. 


\subsection{Accuracy Assessment}

Accuracy assessments, or validation, of remote sensing data, is essential to determine the quality of information derived from it or the reliability of the outputs [62]. It is performed by comparing the outputs from remote sensing analysis to a predetermined set of reference data. The accuracy assessment result demonstrates the closeness of the information extracted from the remote sensing data to the reference data. Table 3 summarises the distribution of the reference data type and validation methods used for assessment purposes for all except six of the selected documents. These six documents did not disclose the reference data or validation method adopted in their research $[54,57,63-65]$. Out of 68 documents, 55 documents (more than $80 \%$ ) used ground data with/without other data for reference purposes. Of these, 15 documents used ground data with high-resolution images for accuracy assessment using the error matrix with Kappa coefficient. Ground data are widely accepted for accuracy assessment of remote sensing image classification [66]. These data are normally collected through field visits. Among the ground data collected were global positioning system (GPS) points, geo-referenced photos, and physical parameters of trees, such as diameter. Aside from that, researchers also used high-resolution imagery primarily obtained from Google Earth while others used related data produced by government authorities (e.g., topographic maps, land-use map, statistical data). The high-resolution imagery from Google Earth is accessible and easy to retrieve, which may explain the reason behind its widespread use in accuracy assessment.

Table 3. Distribution of reference data type and validation methods used with the respective number of documents.

\begin{tabular}{|c|c|c|c|c|c|c|}
\hline \multirow{2}{*}{ Reference Data } & \multicolumn{3}{|c|}{ Error Matrix } & \multirow[b]{2}{*}{$\begin{array}{c}\text { Kappa } \\
\text { Coefficients }\end{array}$} & \multirow[b]{2}{*}{$\begin{array}{l}\mathbf{R}^{2} / \\
\text { RMSE }\end{array}$} & \multirow[b]{2}{*}{$\begin{array}{l}\text { Total Number of } \\
\text { Documents }\end{array}$} \\
\hline & $\begin{array}{l}\text { with Kappa } \\
\text { Coefficients }\end{array}$ & $\begin{array}{c}\text { without } \\
\text { Kappa } \\
\text { Coefficients } \\
\end{array}$ & $\begin{array}{c}\text { with } \mathbf{R}^{2} / \\
\text { RMS Error }\end{array}$ & & & \\
\hline $\begin{array}{c}\text { Ground data } \\
\text { Example: Sampling point, } \\
\text { field survey, GPS point and } \\
\text { geotagged photo }\end{array}$ & 5 & 7 & 3 & 1 & 8 & 24 \\
\hline $\begin{array}{c}\text { Images } \\
\text { Example: Google Earth } \\
\text { imagery, aerial orthophoto, } \\
\text { Ikonos image }\end{array}$ & 3 & 3 & 0 & 0 & 0 & 6 \\
\hline $\begin{array}{c}\text { Other data } \\
\text { Example: Maps (land-use, } \\
\text { topographic, statistical } \\
\text { data, etc.) }\end{array}$ & 2 & 0 & 0 & 0 & 2 & 4 \\
\hline $\begin{array}{c}\text { Combination of: } \\
\text { Ground data + images } \\
\text { Ground data + other data } \\
\text { Ground data + images + } \\
\text { other data } \\
\text { Images + other data }\end{array}$ & $\begin{array}{c}15 \\
2 \\
3 \\
2\end{array}$ & $\begin{array}{l}2 \\
4 \\
2 \\
1\end{array}$ & $\begin{array}{l}0 \\
1 \\
0 \\
0\end{array}$ & $\begin{array}{l}0 \\
0 \\
0 \\
0\end{array}$ & $\begin{array}{l}0 \\
2 \\
0 \\
0\end{array}$ & $\begin{array}{c}17 \\
9 \\
5 \\
3\end{array}$ \\
\hline Total number of documents & 32 & 19 & 4 & 1 & 12 & 68 \\
\hline
\end{tabular}

A total of 55 documents used the error matrix method. From these, 32 documents provided Kappa coefficients together with the error matrix results. This method was widely used because most of the selected studies focused on the land use/land cover (LULC) method of rubber mapping, making the error matrix the most appropriate measure for thematic classification accuracy. Only one document reported the Kappa coefficient without the error matrix result, while 12 documents presented the coefficient of determination ( $R$ squared or $R^{2}$ ) with/or root mean square error (RMSE) value to evaluate the accuracy of 
their results. These values were reported only when the study involved statistical analyses or the development of a model.

\subsection{Application Categories}

The current application of remote sensing in rubber plantations can be categorised into six subject areas: (1) Mapping; (2) change detection; (3) stand age; (4) biomass and carbon estimation; (5) leaf area index estimation and (6) disease detection. The selected documents were grouped into these subject areas based on the study's primary objective. When the documents incorporated more than one subject area, it was classified based on the most dominant subject area.

Figure 6 shows the distribution of documents that fall into each subject area. There were 24 documents that focused on rubber plantation mapping. This was followed by plantation area change detection, and stand age, with 20 and 15 studies, respectively. These three subject areas were most likely dominant in the selected studies because they were dependent on basic classifications and methods. The other subject areas were more complex and required additional understanding of the subject matter.

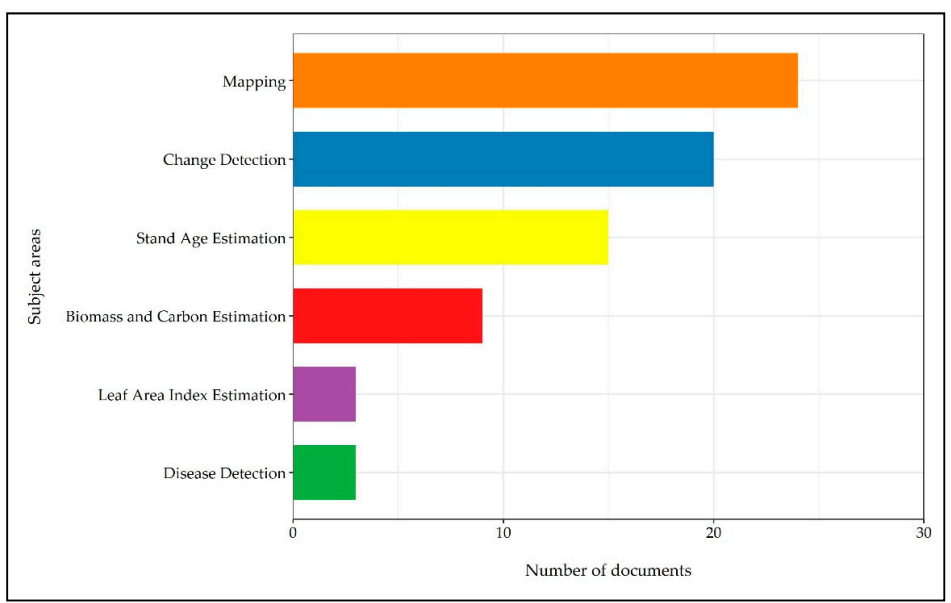

Figure 6. Distribution of the selected documents in each subject area.

It is important to point out that the disease detection subject area had least number of documents. A possible explanation could be that such studies are limited by the occurrence of the disease, which can be infrequent, and the scale of the incident, which needs to be large enough to be detected by satellite images. One document [15] had used satellite images to monitor Phytophthora leaf disease, which is caused by fungus. Interestingly, the study demonstrated that remote sensing techniques can facilitate the detection of leaf disease.

\section{Remote Sensing Application in the Study of Rubber Plantations}

In this section, we discuss the subject areas identified in the previous subsection in further detail, with a focus on the approaches and methods adopted in the selected studies. Figure 7 shows an overview of the documents in each subject area and study area conducted. 


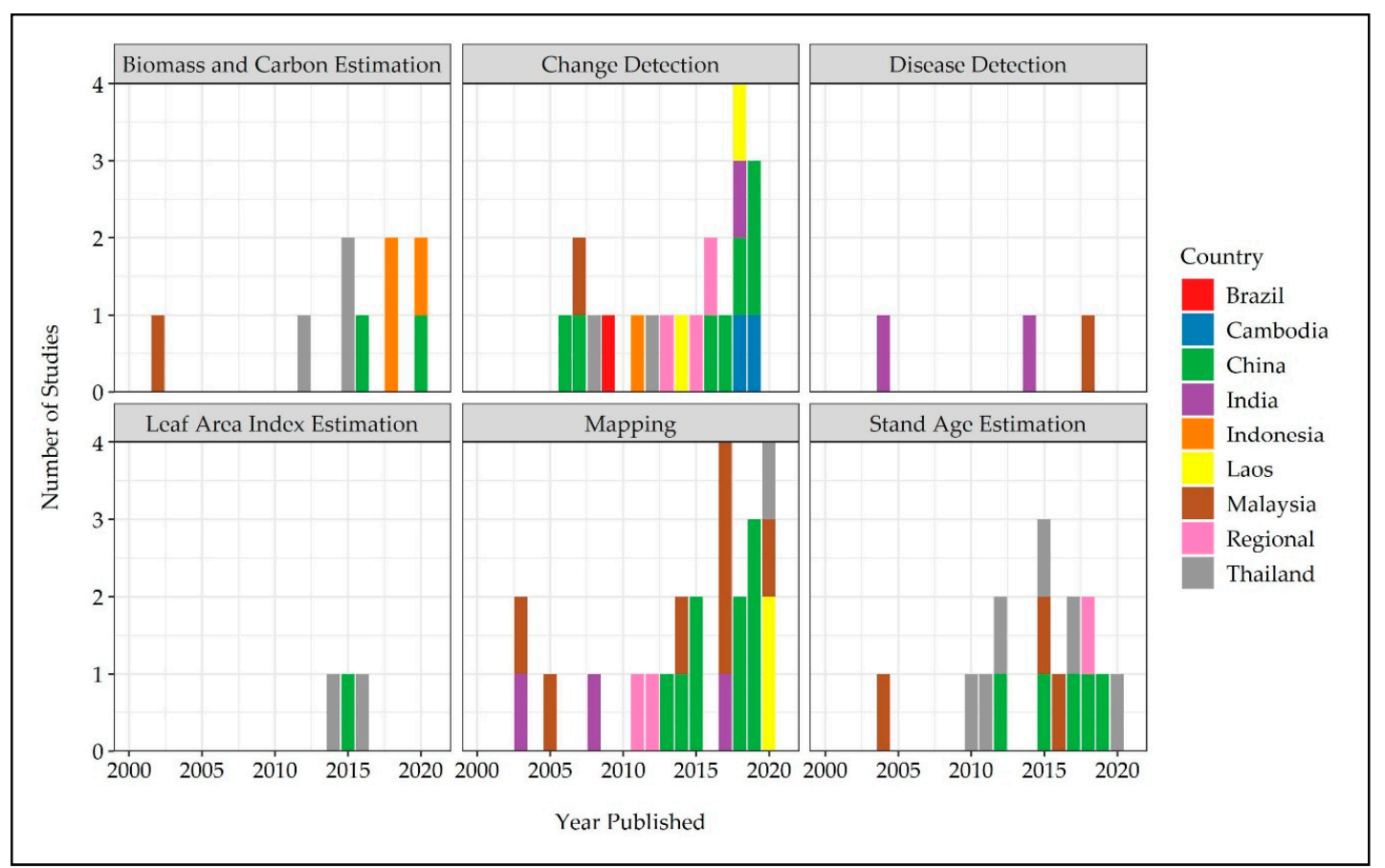

Figure 7. Distribution of the documents in each subject area based on the study area.

\subsection{Plantation Mapping}

Plantation mapping is an elementary process in developing a good database for plantation management. It serves as a foundation for all management processes. It is crucial to have a reliable and up-to-date rubber plantation inventory, along with other associated data, for management purposes. Two-thirds of the documents in this subject area conducted a land use/land cover (LULC) study aimed at mapping the greater extent of plantations. The analysis was employed to classify the study areas into several LULC types such as rubber, forest, oil palm, built-up area and others (e.g., [18]). Other studies in this subject area have only classified study areas into two classes: Rubber and non-rubber area $[39,58,67]$.

Different image classification methods were applied in order to detect rubber through LULC classification. These include pixel-based (supervised) and object-based classification. Table 4 compares the classification method used in mapping rubber plantation with its respective sensor and overall accuracy results from the error matrix assessment. The most common approach in mapping rubber plantations using remote sensing was conventional supervised classifiers. Among the supervised classifiers used were Maximum Likelihood algorithm [18,65,67]; Mahalanobis typicalities [36]; Mahalanobis with multi-layer perceptron neural network [68]; Mahalanobis and Maximum Likelihood [69] and Decision Tree [58,70]. Random Forest classification has been employed in a recent study to investigate the textural feature's effect on the classification of rubber plantations [71]. There were no studies that adopted the unsupervised classification method.

For the object-oriented approach classification, Dai et al. [73] used the K-Nearest Neighbour classification during the period of defoliation to delineate the study area. Two other documents compared pixel- and object-based classification methods to identify the rubber plantations in the study area [29], as well as various spectral vegetation indices [79]. Supervised classification approaches offer managers and smallholders a more user-friendly method compared with other methods for mapping rubber plantations. 
Table 4. Comparison of classification and overall accuracy for mapping rubber plantations.

\begin{tabular}{|c|c|c|c|}
\hline Sensor & Classification & Overall Accuracy & Reference \\
\hline IRS & $\begin{array}{l}\text { False colour composite and vegetation } \\
\text { indices }\end{array}$ & $\mathrm{n} / \mathrm{a}$ & [38] \\
\hline $\mathrm{TM}$ & Maximum Likelihood & $97.2 \%$ & [18] \\
\hline $\mathrm{TM}$ & $\begin{array}{c}\text { Maximum Likelihood for logistic } \\
\text { regression }\end{array}$ & $87.0 \%$ & [67] \\
\hline LISS III & Maximum Likelihood & $97.0 \%$ & [65] \\
\hline ASTER & Mahalanobis with neural network & $99.7-98.7 \%$ & [68] \\
\hline MODIS & Mahalanobis typicality & $98.1-98.1 \%$ & [36] \\
\hline $\begin{array}{l}\text { TM, ETM+, } \\
\text { PALSAR }\end{array}$ & Phenology-based algorithm-using VIs & $92.0 \%$ & [72] \\
\hline $\mathrm{TM}$ & Maximum Likelihood and Mahalanobis & $91.2 \%$ & [69] \\
\hline $\mathrm{TM}$ & k-Nearest Neighbour & $90.0 \%$ & [73] \\
\hline $\begin{array}{l}\text { TM, ETM+, } \\
\quad \text { OLI }\end{array}$ & Phenology-based algorithm-using VIs & $89.9 \%$ & [74] \\
\hline OLI & Phenology-based algorithm-using VIs & $92.0-96.0 \%$ & [39] \\
\hline $\begin{array}{l}\text { TM, ETM+, } \\
\text { OLI }\end{array}$ & Support Vector Machine & $97.1 \%$ & [59] \\
\hline SPOT-5 & $\begin{array}{l}\text { Mahalanobis distance (MD), k-Nearest } \\
\text { Neighbour (k-NN), Support Vector } \\
\text { Machine (SVM) and Decision Tree (DT) }\end{array}$ & $80.8-97.5 \%$ & [29] \\
\hline IRS & Visual interpretation and vectorization & $95.2 \%$ & [75] \\
\hline $\begin{array}{c}\text { TM, } \\
\text { PALSAR }\end{array}$ & Decision Tree & $87.5 \%$ & [70] \\
\hline OLI & Decision Tree & $92.2 \%$ & [58] \\
\hline $\begin{array}{l}\text { MODIS, } \\
\text { TM, ETM+, } \\
\text { PALSAR }\end{array}$ & Pixel- and object- based with phenology & $72.7-91.0 \%$ & [76] \\
\hline $\begin{array}{l}\text { MODIS, TM, } \\
\text { ETM+, OLI }\end{array}$ & $\begin{array}{l}\text { Fused time series indices (NDVI, EVI, } \\
\text { NDMI, NBR, and TCA) }\end{array}$ & $89.5 \%$ & [31] \\
\hline OLI & $\begin{array}{l}\text { Phenology-based algorithm using } \\
\text { renormalized modified normalized burn } \\
\text { ratio (RMNBR) index }\end{array}$ & $94.8 \%$ & [77] \\
\hline OLI & $\begin{array}{l}\text { Phenology-based algorithm using } \\
\text { re-normalization of two vegetation } \\
\text { moisture indices (NDVI and NDM) }\end{array}$ & $92.3 \%$ & [78] \\
\hline OLI & $\begin{array}{l}\text { False Colour Method, Unsupervised } \\
\text { Classification, Supervised Classification } \\
\text { and Spectral Vegetation Indices (SVIs) }\end{array}$ & $81.0-83.0 \%$ & [79] \\
\hline Sentinel-2 & $\begin{array}{l}\text { Phenology-based algorithm using } \\
\text { Red-edge Spectral Indices (RESI) }\end{array}$ & $92.5 \%$ & [80] \\
\hline OLI & $\begin{array}{l}\text { Phenology-based algorithm using } \\
\text { difference Normalized Burn Ratio (NBR) }\end{array}$ & $93.3 \%$ & [81] \\
\hline $\begin{array}{l}\text { Sentinel-1, } \\
\text { Sentinel-2, } \\
\text { GF-1, OLI }\end{array}$ & Spectral and textural features & $90.36-92.38 \%$ & [71] \\
\hline
\end{tabular}

Based on the Table 4, very high overall accuracies were achieved from the supervised classification of Maximum Likelihood, Mahalanobis, Support Vector Machine and K-nearest 
neighbour. The overall accuracy of these algorithms was evaluated on the produced map of several land use. It can be seen that the application of the same algorithm can provide different results. For example, while adopting the Decision Tree algorithm, Dibs et al. [29], Shidiq et al. [70] and Han et al. [58] reported an accuracy of $80.8 \%, 87.5 \%$ and $92.2 \%$, respectively. The results are influenced by parameters such as: (1) The remote sensing dataset used; (2) the reference data set; and (3) the physical characteristics of study location $[82,83]$.

Studies conducted between 2003 and 2012 were primarily focused on simple rubber area recognition. More recently, researchers have adopted more complex measures such as the exploitation of rubber's unique phenological characteristics (called wintering, which involves defoliation and refoliation), in the delineation of rubber trees plantations [59,81]. Most rubber leaves fall off during the defoliation process before new leaves start to emerge in the refoliation process [4]. From a remote sensing perspective, this characteristic makes rubber plantations clearly distinct from other land cover types such as forest and oil palm, meaning that rubber detection, identification and classification is highly accurate. This characteristic also helps to identify and outline rubber plantations within fragmented tropical mountainous lands [76]. Two studies have extracted phenological time phase information to help distinguish rubber while adopting Decision Tree [72] and pixel and object-based approaches [76].

Researchers have developed multiple phenology-based algorithms using vegetation indices derived from Landsat $[39,53,74,78,81]$ and Sentinel [80]. Studies that have applied phenology-based algorithms on images to map rubber plantations have shown three advantages: (1) It is easier to distinguish rubber from natural forest and cropland [39]; (2) it improves classification results [39,58,74]; and (3) it generates reliable and accurate maps of rubber areas.

\subsection{Change Detection}

In remote sensing, change detection is a process of identifying differences in land features at different times. Rubber plantation change detection studies are primarily focused on estimating the expansion or reduction of the planting area. Findings from these studies highlight two major points. First, most of the study areas were experiencing a period of expansion. The largest planting area expansion was detected in Xishuangbanna, China, which increased six times between 1987 and 2018 [77,84]. It is thought that the expansion was driven by attractive economic returns $[57,85,86]$ derived from the increase in rubber prices between 2001 and 2011 [87]. Second, global rubber expansion has occurred at the natural forest's cost [88]. Although rubber expansion has boosted smallholders' income by almost ten times [89], the conversion of natural forest into monoculture rubber plantation has resulted in the loss of biodiversity $[85,90]$.

Change detection in general has become more feasible due to freely available satellite images. Land use/land cover change (LULCC) detection is used to observe and evaluate land feature changes based on produced land use/land cover maps performed using multitemporal image datasets [91-93]. Selected studies in this subject area have analysed LULCC through several classification methods. This technique has been useful in monitoring the rubber area expansion and reduction at local [85] and regional scale [88].

In the case of rubber LULCC detection, three main classification methods were adopted to map land use/land cover. The methods include: (1) Visual interpretation $[19,63]$; $(2)$ pixel and object-based classifications; and (3) phenology-based algorithms. Table 5 highlights the classification method, temporal period and accuracy obtained in the studies of change detection in rubber plantations. Four documents used the popular method of supervised classification using the Maximum Likelihood algorithm to investigate rubber expansion $[57,64,94,95]$. Other supervised algorithms used were Decision Tree [62,96-98] and shapelet based algorithms [99]. Grogan et al. [88] used the Landtrendr algorithm to study forest disturbance due to rubber area increment. Vadjunec et al. [100] adopted the hybrid classification of unsupervised and supervised approaches to develop 12 classes of 
land-use maps from Landsat TM and ETM+ images. Apart from the pixel-based approach, two studies have used the object-based approach to classify land covers [85,101]. Instead of using available classification methods, two recent documents $[77,84]$ used a self-developed phenology-based algorithm to monitor rubber expansion.

Table 5. Comparison of classification and overall accuracy for change detection studies in rubber plantations.

\begin{tabular}{|c|c|c|c|c|c|}
\hline Sensor & Classification & Temporal Period & Previous Land Cover & Accuracy & Reference \\
\hline TM, ETM+ & Supervised classification & 1998 to 2003 & $\begin{array}{l}\text { Forests, shifting } \\
\text { agriculture }\end{array}$ & $\mathrm{OA}=>80 \%$ & [89] \\
\hline $\mathrm{TM}$ & $\begin{array}{l}\text { Supervised classification } \\
\text { (Maximum Likelihood) }\end{array}$ & $\begin{array}{l}1989 \text { to } 1993 \\
1993 \text { to } 1999\end{array}$ & $\mathrm{n} / \mathrm{a}$ & $\mathrm{n} / \mathrm{a}$ & [64] \\
\hline MSS, TM, ETM+ & $\begin{array}{l}\text { Supervised classification } \\
\text { (Maximum Likelihood) }\end{array}$ & 1976 to 2003 & forest & $\mathrm{OA}=90.1 \%$ & [94] \\
\hline MSS, TM, ETM+ & $\begin{array}{l}\text { Supervised classification } \\
\text { (Maximum Likelihood) }\end{array}$ & $\begin{array}{l}1976 \text { to } 1990 \\
1990 \text { to } 2006\end{array}$ & Forest and paddy & $\mathrm{n} / \mathrm{a}$ & [57] \\
\hline TM, ETM+ & $\begin{array}{c}\text { Hybrid } \\
\text { unsupervised/supervised }\end{array}$ & 1986 to 2003 & Forest & $\mathrm{OA}=85.0 \%$ & [100] \\
\hline MSS, TM, ETM+ & Object-based & 1973 to 2005 & Forest & $\mathrm{OA}=89.3 \%$ & [102] \\
\hline THEOS & Supervised classification & 2002 to 2011 & Forest and paddy & Kappa $=0.87$ & [19] \\
\hline $\begin{array}{l}\text { MSS, TM, ETM+, } \\
\text { MODIS }\end{array}$ & $\begin{array}{l}\text { Newly proposed vegetation } \\
\text { indices (Planted density) }\end{array}$ & $\begin{array}{l}1980 \text { to } 2010 \\
1990 \text { to } 2010 \\
2000 \text { to } 2010\end{array}$ & Forest & $\mathrm{OA}=82.3-86.9 \%$ & [32] \\
\hline ETM+ & $\begin{array}{c}\text { Principal component analysis } \\
\text { (PCA) and spectral vegetation } \\
\text { index (NDVI) }\end{array}$ & $\begin{array}{l}2003 \text { to } 20062006 \text { to } \\
20092009 \text { to } 2012\end{array}$ & Forest & $\mathrm{OA}=87.0 \%$ & [103] \\
\hline TM, ETM+, MODIS & $\begin{array}{l}\text { Supervised classification } \\
\text { (LandTrendr classification) }\end{array}$ & 2000 to 2012 & Forest & $\mathrm{OA}=86.0 \%$ & [88] \\
\hline TM, ETM+, RapidEye & Object-based & $\begin{array}{l}1988 \text { to } 2002 \\
2002 \text { to } 2010\end{array}$ & Forest & $\begin{array}{c}\mathrm{OA}= \\
87.5 \%-88.7 \%\end{array}$ & [85] \\
\hline TM, ETM+ & $\begin{array}{l}\text { Supervised classification } \\
\text { (Decision Tree) }\end{array}$ & 2000 to 2010 & Paddy and woodland & $\mathrm{OA}=86.59 \%$ & [97] \\
\hline TM, ETM+, OLI & $\begin{array}{l}\text { Supervised classification } \\
\text { (Decision Tree) }\end{array}$ & $\begin{array}{l}1989 \text { to } 2000 \\
2000 \text { to } 2013\end{array}$ & Forest & $\mathrm{OA}=83.9-86.5 \%$ & [62] \\
\hline TM, ETM+, OLI & $\begin{array}{l}\text { Supervised classification } \\
\text { (shapelet-based) land } \\
\text { clearing-establishment of } \\
\text { rubber plantation }\end{array}$ & 1995 to 2015 & Forest and non-forest & $\mathrm{OA}=89.0 \%$ & [99] \\
\hline LISS III & Visual interpretation & 1997 to 2013 & Forest & $\mathrm{n} / \mathrm{a}$ & [63] \\
\hline TM, ETM+ & $\begin{array}{l}\text { Supervised classification } \\
\text { (Decision Tree) }\end{array}$ & 2004 to 2012 & Forest & $\mathrm{OA}=92.0 \%$ & [96] \\
\hline $\begin{array}{l}\text { TM, ETM+, MODIS, } \\
\text { PALSAR }\end{array}$ & Phenology-based algorithm & 2000 to 2010 & Forest & $\mathrm{OA}=95.0 \%$ & [98] \\
\hline $\begin{array}{l}\text { MODIS, OLI, } \\
\text { Sentinel-2 }\end{array}$ & $\begin{array}{l}\text { Random Forest classifier, } \\
\text { Breaks For Additive Season } \\
\text { and Trend (BFAST), and } \\
\text { non-parametric regression }\end{array}$ & 2001 to 2015 & Forest & $\mathrm{OA}=86.0 \%$ & [87] \\
\hline TM, ETM+, OLI & $\begin{array}{l}\text { Phenology-based algorithm } \\
\text { (change rate of the } \\
\text { Landsat-derived normalized } \\
\text { burn ratio) }\end{array}$ & $\begin{array}{l}1996 \text { to } 2000 \\
2001 \text { to } 2005 \\
2006 \text { to } 2010 \\
2011 \text { to } 2015\end{array}$ & Forest & $\mathrm{OA}=92.0-97.0 \%$ & [53] \\
\hline TM, ETM+, OLI & $\begin{array}{l}\text { Phenology-based multiple } \\
\text { normalization }\end{array}$ & 1987 to 2018 & Forest & $\mathrm{OA}=94.7 \%$ & [84] \\
\hline
\end{tabular}

As seen in the Table 5, five studies show an overall accuracy higher than $90 \%$. Three from these studies used phenology-based algorithm, while another used Maximum Likelihood and Decision Tree supervised method. However, it is difficult to identify the 
best-suited change detection method, as several factors may affect the selection criteria [82]. The factors are remote sensing data resolutions, quality of data, physical characteristics of features of interest, atmospheric effect, image registration and study area size [83].

According to Food and Agriculture Organization (FAO) [2], the global area under rubber plantations expanded by $25 \%$ over the 2008-2018 decade. This equates to an annual increase of 3\% over this period and $90 \%$ of this expansion occurred in Asia. Chakraborty et al. [63] also stated that rubber could expand four-fold by 2050. Accurate information on rubber expansion, particularly from a spatial and temporal perspective, is essential for policymakers to formulate, monitor and plan strategic land use policy. Studies included in this literature indicate that some regions have already implemented regulations to control rubber expansion in natural forest areas [100]. Change detection study is also vital in evaluating rubber's impact on the environment [96].

\subsection{Stand Age Estimation}

Rubber trees are tapped after four to eight years of planting [104] or more commonly after seven years $[105,106]$. Generally, under good agricultural practices, latex production peaks at 20 years before the yield starts to stagnate and decline. After the economic lifespan of 30 to 35 years, trees are often cut down for timber production. Therefore, information on rubber stand age is crucial for rubber plantation management because it indicates latex production level.

In predicting rubber plantation stand ages, three practical approaches were adopted by the identified studies [107]: (1) Statistical models; (2) image classification and (3) land use land cover change (LULCC) detection. Table 6 details the approach, age resolution and accuracy obtained in the studies of stand age estimation for rubber plantations. It is noticeable that different age resolution or groups were defined and used in these studies. Due to the different approaches and age groups, multiple accuracy assessments were used.

Table 6. Comparison of approach method, age resolution and accuracy in stand age estimation studies of rubber plantations.

\begin{tabular}{|c|c|c|c|c|}
\hline Sensor & Approach & Age Resolution & Accuracy & Reference \\
\hline Landsat TM & Statistical Model & - & RMSE $=6.4-8.2$ years & [108] \\
\hline Landsat 8 & Statistical Model & $5,10,15$ and 20 & $\mathrm{R}^{2}=0.4335-0.4912$ & [109] \\
\hline Landsat TM & Statistical Model & - & RMSE $=5.96$ years & [110] \\
\hline EO-1 Hyperion & Statistical Model & $5-25$ & $\begin{array}{c}\mathrm{R}^{2}=0.624 \\
\mathrm{RMSE}=2.625 \text { years }\end{array}$ & [55] \\
\hline Landsat TM, Landsat 7, Landsat 8 & Statistical Model & $3-15$ & $\mathrm{OA}=87 \%$ & [111] \\
\hline SPOT-2, SPOT-4, SPOT-5, THEOS & Image Classification & $<5,5-10$ and $>10$ & $\mathrm{OA}=89.8 \%$ & [112] \\
\hline Landsat TM & Image Classification & $\leq 2,2-4,>4$ & - & [113] \\
\hline THEOS & Image Classification & $<5,5-10$ and $>10$ & Kappa: $0.627-0.677$ & [86] \\
\hline Pléiades & Image Classification & $\leq 7,7-15,>15$ & $\mathrm{OA}=94-97 \%$ & [114] \\
\hline SPOT-5 & Image Classification & $\leq 7,7-25,>25$ & $\mathrm{OA}=77-91 \%$ & [115] \\
\hline $\begin{array}{c}\text { Landsat TM, } \\
\text { Landsat 7, } \\
\text { Landsat } 8\end{array}$ & Image Classification & Annual & $\mathrm{OA}=84.4-84.7 \%$ & [116] \\
\hline Landsat TM/ETM+, PALSAR & LULCC Detection & $\leq 5,6-10,>10$ & $\mathrm{OA}=85 \%$ & [98] \\
\hline Landsat TM, Landsat 7 & LULCC Detection & Annual & RMSE $=2.5$ years & [117] \\
\hline TM/ETM+/OLI & LULCC Detection & Annual & $\begin{array}{c}\mathrm{R}^{2}=0.85 / 0.99 \\
\mathrm{RMSE}=2.34 / 0.54 \text { years }\end{array}$ & [107] \\
\hline Landsat TM, Landsat 7, Landsat 8 & LULCC Detection & $\begin{array}{l}\leq 5,6-10,11-15,16-20 \\
21-25,26-30, \text { and } \geq 31\end{array}$ & $\mathrm{OA}=92.8 \%$ & [118] \\
\hline
\end{tabular}

In the statistical models, correlation analysis was used to develop models by establishing relationships between rubber plantation stand ages and spectral reflectance [108-110], and/or vegetation indices $[55,111]$. For the image classification approach, different classifi- 
cation techniques were used to recognise multiple rubber stand age groups. Studies applied supervised classifications such as Maximum Likelihood [86,114]; Mahalanobis [68]; and Spectral Angle Mapper [115]. In these studies, rubber plantations were divided into age groups categorised by maturity or latex production level [115], rubber growth phenology and field management trees [118], or simply based on the availability of field data [36,114]. For instance, Dib and Mansor [115] developed three age classes based on latex production level; $<7$ years, $7-20$ years, and $>25$ years to represent the no latex, high latex, and low latex production period, respectively.

There were no standard age groups developed by any of the studies. The ability to develop such a standard may have been hindered by the fact that most rubber plantations are multiclonal - this is a common practice to avoid yield losses. Different rubber clones have different growth rates and maturation age, which creates in-field variability. In addition to this, environmental factors (e.g., soil and weather), and management practices (e.g., fertiliser), also influence rubber growth.

LULCC detection was used to identify the establishment year of rubber trees through ground landscape changes. New plantation establishment often involves the common practice of land clearing and transplanting rubber seedlings. These specific events are used to estimate rubber stand age. To date, four documents [107,117-119], categorised under the LULCC approach, used various vegetation indices and non-visible spectral bands to identify the establishment year of a rubber plantation. Although this approach predicts rubber age accurately, the age of older rubber plantations cannot be estimated if land clearing or transplanting cannot be detected remotely. Ground reference data of the cleared area is crucial to confirm that the area is planted with rubber trees.

The identification of rubber stand age can help government agencies predict latex production at a local, regional, and national scales. This data may be useful in forecasting timber production from the plantation. Considering the long economic life of rubber, stand age information is essential as it is also a primary indicator for monitoring biomass [108] and assessing carbon stocks [120].

\subsection{Biomass and Carbon Estimation}

Rubber trees are typically grown for approximately 25 to 35 years before being felled for timber production. The total carbon stock of rubber in plantations has been estimated to be higher than many tropical forestry and agroforestry systems [121]. The time-average carbon stock of lowland and highland rubber plantations is estimated to be $58 \mathrm{MgC} / \mathrm{ha}$ and $28 \mathrm{MgC} /$ ha respectively [106]. The role of rubber in mitigating climate change has been recognised globally [122-124]. Therefore, the accurate estimation of biomass and carbon stock in rubber plantations has become more critical than previously.

A conventional method of calculating a tree's biomass involves cutting down sample trees and weighing their different components [125]. However, this method is undesirable because it is destructive and limited to small, accessible areas [126]. Researchers have used rubber plantation maps produced from remotely sensed data to estimate biomass and carbon. In studying rubber plantation biomass, all studies primarily focused on aboveground biomass (AGB). The study of carbon stocks in rubber plantations is derived from the AGB estimations.

Table 7 shows the comparison of method, accuracy and sensor used in the studies focused on biomass and carbon estimation. A majority (seven out of nine) documents within this subject area applied specific allometric equations to predict AGB and carbon of rubber plantations, and correlated these estimates with satellite image datasets [106,127-132]. The developed biomass and carbon estimation models were created using several methods: (1) Vegetation indices models [130,132]; (2) computational models [129,133] and (3) tree growth parameter models [127,128]. 
Table 7. Comparison of method and accuracy in biomass and carbon estimation related studies.

\begin{tabular}{|c|c|c|c|c|}
\hline Sensor & Allometric Equation & Method & Accuracy & Reference \\
\hline Landsat TM & No & $\begin{array}{l}\text { Maximum-likelihood for } \\
\text { logistic regression }\end{array}$ & RMSE $=6.4-8.2$ years & [49] \\
\hline THEOS & Yes & $\begin{array}{l}\text { Tree growth parameter models } \\
\text { (object-based classification) }\end{array}$ & $\mathrm{R}^{2}=0.36$ & [127] \\
\hline THEOS & Yes & $\begin{array}{l}\text { Tree growth parameter models } \\
\text { (object-based classification) }\end{array}$ & $\begin{array}{c}\mathrm{R}^{2}=0.531-0.865 \\
\mathrm{RMSE}=0.39-1.93 \mathrm{t} / \mathrm{ha} \\
\mathrm{RMSE}=0.17-11.97 \\
\mathrm{tC} / \mathrm{ha}\end{array}$ & [128] \\
\hline Worlview-2 & Yes & $\begin{array}{l}\text { Supervised- Stepwise Linear } \\
\text { regression and Artificial neural } \\
\text { network models }\end{array}$ & Карра $=0.627-0.677$ & [129] \\
\hline $\begin{array}{l}\text { IKONOS, SPOT, } \\
\text { RapidEye, Landsat }\end{array}$ & Yes & $\begin{array}{l}\text { Rapid Carbon Stock Appraisal } \\
\text { (RaCSA) method }\end{array}$ & $\mathrm{R}^{2}=0.968-0.982$ & [106] \\
\hline ASTER & No & Vegetation index (MSAVI) & $\mathrm{R}^{2}=0.709$ & [130] \\
\hline ASTER & Yes & Vegetation index model (MSAVI) & $R^{2}=0.681$ & {$[131]$} \\
\hline Sentinel-2 & Yes & $\begin{array}{c}\text { Vegetation indices model } \\
\text { (RVI, NDVI, ARVI, and SARVI) }\end{array}$ & $\mathrm{R}^{2}=0.473$ & [132] \\
\hline $\begin{array}{l}\text { Landsat 7, } \\
\text { Landsat 8, } \\
\text { Sentinel-2 }\end{array}$ & Yes & $\begin{array}{l}\text { Regression and Random } \\
\text { Forest model }\end{array}$ & $\begin{array}{c}\mathrm{R}^{2}=0.82-0.96 \\
\mathrm{RMSE}=4.08-10.59 \\
\mathrm{Mg} / \text { ha biomass }\end{array}$ & [133] \\
\hline
\end{tabular}

Two studies calculated the vegetation indices using specific bands of selected remote sensing data to correlate with biomass and carbon stock derived from the allometric equations. Anurogo et al. [130] used the Modified Soil Adjusted Vegetation Index (MSAVI) and found that MSAVI offered a moderate relationship to biomass with $\mathrm{R}^{2}$ of 0.681 . Alternatively, Pratama [132] studied four different vegetation indices to identify the most appropriate vegetation indices to accurately estimate carbon stock. The vegetation indices are: Ratio Vegetation Index (RVI), Normalised Difference Vegetation Index (NDVI), Atmospheric Resistant Vegetation Index (ARVI) and Soil and Atmospherically Resistant Vegetation Index (SARVI). The ARVI-based estimation model for the exponential regression type had an accuracy of $84.4 \%$ (supported by $\mathrm{R}^{2}=0.522$ ).

Yasen and Koedsin [129] have used eight spectral bands from WorldView-2 imagery as inputs to develop stepwise multiple linear regression (SMLR) and artificial neural network (ANNs) models. The performance of the two biomass models was evaluated. The ANNs model showed higher $\mathrm{R}^{2}(0.66)$ than the SMLR model (0.33). This finding was in line with two other studies $[134,135]$ that reported the ANNs provided better estimation than SMLR in estimating biomass. Another study [133] used a combination of Landsat-Sentinel 2 based variables with a stand age parameter data to develop several biomass models based on a regression and Random Forest algorithm. The finding indicates that the stand age parameter has improved the prediction accuracy of rubber plantation biomass. A hybrid model integrating the optimal results from both regression and Random Forest models provide better performance in predicting biomass ( $\mathrm{R} 2=0.83$ and RMSE $=12.48 \mathrm{Mg} / \mathrm{ha}) . "$

Charoenjit et al. $[127,128]$ used spectral and textural parameters as inputs into their tree girth/age models, which were created using object-based image analysis. Both studies first classified rubber trees into three age groups, with the age range for each class (young, middle and old) being slightly different. The model accuracy reported for the 2015 study had an RMSE of $0.17 \mathrm{tC} /$ ha.

Overall, remote sensing analysis for biomass and carbon stock estimation in rubber plantations shows moderate accuracy. Further studies need to be conducted to find the most suitable methods delivering higher accuracy. Studies in this subject area were only a 
snapshot conducted at a specific time. Thus, future studies should consider conducting multi-temporal analysis to monitor biomass and carbon stock over time.

\subsection{Leaf Area Index Estimation}

Leaf area index (LAI) refers to the ratio of upper leaf surface area to ground area in broadleaf canopies [136]. LAI is a commonly used parameter in predicting biomass [137]. The LAI values are also a beneficial indicator of plant canopy structure and density [105]. Highly accurate predicted values can play an essential role in rubber plantation management [138].

However, in rubber, researchers primarily used this biophysical characteristic as an indicator for evaluating the physical conditions of rubber plantations [56] and to predict latex yield $[33,139]$. Three studies have estimated the LAI values through regression models $[33,56,139]$. These studies are listed in Table 8.

Table 8. Comparison of method and accuracy for leaf area index (LAI) studies in rubber plantations.

\begin{tabular}{|c|c|c|c|}
\hline Sensor & Method & Accuracy & Reference \\
\hline \multirow{4}{*}{$\begin{array}{c}\text { EO-1 } \\
\text { Hyperion }\end{array}$} & $\begin{array}{l}\text { Regression model based on: } \\
\text { Simple Ratio Index }\end{array}$ & $\mathrm{R}^{2}=0.820, \mathrm{RMSE}=0.170$ & \multirow{4}{*}[56]{} \\
\hline & Normalized Difference Vegetation Index & $\mathrm{R}^{2}=0.794, \mathrm{RMSE}=0.162$ & \\
\hline & Modified Simple Ratio Index & $\mathrm{R}^{2}=0.815, \mathrm{RMSE}=0.166$ & \\
\hline & Modified Soil Adjusted Vegetation Index & $\mathrm{R}^{2}=0.775, \mathrm{RMSE}=0.160$ & \\
\hline \multirow{2}{*}{$\mathrm{HJ}-1, \mathrm{ZY} 3$} & Stepwise regression model & $\mathrm{R}^{2}=0.43-0.51, \mathrm{RMSE}=0.52-0.82$ & \multirow{2}{*}{ [33] } \\
\hline & Recurrent neural network model & $\mathrm{R}^{2}=0.54-0.58, \mathrm{RMSE}=0.47-0.71$ & \\
\hline \multirow{2}{*}{ WorldView-2 } & Stepwise regression model & $\mathrm{R}^{2}=0.59, \mathrm{RMSE}=0.49$ & \multirow{2}{*}{ [139] } \\
\hline & Artificial neural network model & $\mathrm{R}^{2}=0.83, \mathrm{RMSE}=0.31$ & \\
\hline
\end{tabular}

One of the studies in this subject area have created LAI prediction models using vegetation indices models or computational models. Kewplang and Vaiphasa [56] studied the capability of hyperspectral data for estimating rubber plantation LAI based on four selected vegetation indices: (1) Simple ratio index $\left(\mathrm{SR}_{705}\right)$; (2) Modified Simple Ratio index (MSR 705 ); (3) Normalized Difference Vegetation Index (NDVI ${ }_{705}$ ) and (4) Modified Soil Adjusted Vegetation Index $\left(\mathrm{MSAVI}_{705}\right)$. The findings show that MSAVI 705 was chosen as the best-fitted model, with $R^{2}$ of 0.775 because it had the lowest RMSE values (0.160) among all the models.

For computational models, Chen et al. [33] predicted the spatial-temporal LAI of rubber plantations on Hainan Island by using a recurrent neural network of Nonlinear AutoRegressive networks with eXogenous inputs (NARX) model. The model was developed using spectral bands and seven vegetation indices in order to capture the LAI dynamics. This model performed well during field validation with $\mathrm{R}^{2}$ of 0.88 and a RMSE of 0.24 , although only moderate R2 of 0.54 to 0.58 was produced when tested on field data. Still, this model showed better results than the stepwise regression model. At the same time, Koedsin and Yasen [139] used spectral bands as input variables for Stepwise Multiple Linear Regression (SMLR) and Artificial Neural Networks (ANNs) models to estimate the LAI of rubber trees in Thailand. The results indicated that the ANNs model gives the most accurate $($ RMSE $=0.31)$ prediction compared to the SMLR model when validating with ground data. Among all models, regardless of the study locations and sensors used, the neural network model showed better performance in predicting LAI for rubber plantations.

In creating regression models, bands and vegetation indices were inserted as inputs to find the highest correlation to the observed LAI. The input with the highest correlation was then used to predict the LAI for the study area. In these studies, different sensor imagery was tested, including EO-1 Hyperion [56], HJ-1A/1B [33], and WorldView-2 [139]. The regression models produced moderate to high $\mathrm{R}^{2}$ (between 0.5 and 0.8 ), indicating the viability of estimating LAI value for rubber plantations. These developed models have 
also demonstrated the viability of retrieving spatial-temporal LAI of rubber plantations through remote sensing data. To date, several satellite-derived LAI products are offered by multiple satellites, for instance, MODIS, SPOT, AVHRR, and Envisat [140]. However, none of the studies has exploited these products to study LAI for rubber plantation.

\subsection{Disease Detection}

One of the main challenges in rubber plantation management is the outbreak of pests and diseases. Rubber diseases can be divided into three categories based on tree structure: Leaf; bark; and root. Several major pest and disease incidences in rubber have been reported over the years [141,142]. For example, abnormal leaf fall, powdery mildew, Colletotrichum leaf spot, and Corynespora leaf fall—which occurred in India in 2015 [14]. While remote sensing offers the ability to detect pest and disease incidences, there have only been three studies undertaken for pest and disease incidence in rubber.

Two platforms were observed to obtain data for the detection, mapping and investigation of disease outbreaks in rubber: Satellite and UAV as in Table 9. Two studies $[15,143]$ used satellite imagery to detect and monitor leaf diseases at plantation level. Ranganath et al. [143] used multi-date imagery from the IRS satellite to evaluate its potential for detecting and monitoring the outbreak of Corynespora and Gloeosporium fungi in rubber plantations in the south of India. They applied the Maximum Likelihood algorithm to delineate healthy and infected rubber trees. On the other hand, Pradeep et al. [15] demonstrated the capability of using leaf area index (LAI) values extracted from the MODIS 15A2 product to monitor abnormal leaf fall caused by Phytophthora sp. in their study area. This was mapped using LISS III 2012 and 2013 data. Both studies attained an accuracy of 82\% from the image classification method used.

Table 9. Comparison of selected parameters on studies conducted to detect rubber tree diseases.

\begin{tabular}{|c|c|c|c|c|c|c|}
\hline Sensor & Platform & Method & Leaf Disease & Accuracy & Location & Reference \\
\hline IRS & Satellite & $\begin{array}{c}\text { Image classification } \\
\text { (Supervised-Maximum } \\
\text { likelihood) }\end{array}$ & $\begin{array}{l}\text { Corynespora } \\
\text { Leaf Fall, } \\
\text { Gloeosporium } \\
\text { Leaf Disease }\end{array}$ & $\mathrm{OA}=82 \%$ & Karnataka, India & [143] \\
\hline IRS, MODIS & Satellite & $\begin{array}{l}\text { Image classification } \\
\text { (Unsupervised-K-means) }\end{array}$ & $\begin{array}{l}\text { Phytophthora } \\
\text { Leaf Fall }\end{array}$ & $\mathrm{OA}=82 \%$ & $\begin{array}{l}\text { Kerala and } \\
\text { Kaniyakumari, } \\
\text { India }\end{array}$ & [15] \\
\hline Drone & UAV & Vegetation index & $\begin{array}{l}\text { Odium Leaf } \\
\text { Disease }\end{array}$ & - & Johor, Malaysia & [54] \\
\hline
\end{tabular}

Mohd Ali et al. [54] conducted leaf disease detection on multiple rubber clones, using data from compact sensors mounted on a UAV. The study was based on two spectral regions: Visible and near-infrared. Eight different rubber clone leaves, at a predefined range of conditions (healthy, unhealthy and severe), were randomly selected for further analysis. All three conditions were able to be detected using the NIR region, demonstrating the capability to extract more information when using higher spatial resolution.

All these studies focus on disease detection, primarily leaf diseases. There was no study conducted on pests, or the bark and root diseases of rubber. This could be due to the fact that: (1) Insects and pests do not cause serious problems [52]; and (2) remote sensing data's inability to capture the changes caused by bark and root disease to a tree. On the other hand, leaf disease typically alters tree structure by reducing the canopy or changing the characteristic of the leaves, which makes it far more detectable with optical remote sensing. While this implicitly affects latex yield, if the tree's canopy is in severe condition, with fewer long-term leaves, the reduced canopy can change a spectral bands' reflectance and absorbance. On the other hand, rubber bark and root disease cannot be detected and examined using optical remote sensing imagery because the symptoms or affected spots 
are unable to be seen. This may be the reason why all studies identified in disease detection have focused on leaf diseases. Future studies could look into the possibilities of using changes in other biophysical properties as an indicator of root and bark diseases

\section{Discussion}

Remote sensing technology, particularly satellite technology, remains a critical data source for continuous monitoring of vegetation dynamics at large scales. Although remote sensing offers numerous benefits, challenges remain in the application of the technology to rubber plantations. This section discusses both benefits and challenges in the application of remote sensing in a rubber plantation context. We also analyse and discuss future potential applications.

\subsection{Benefits}

Remote sensing techniques have widely improved the ability to map plantations, track changes in rubber acreage, detect rubber stand age, estimate carbon, biomass, and LAI, and detect rubber leaf diseases. In this section, four main benefits are emphasised and discussed. First, remote sensing imagery enables a larger area of plantation to be studied. Image mosaicking allows the combination of multiple scenes or tiles for large study areas. Plantation areas located in mountainous landscapes, and those without proper access roads, can be effectively mapped for monitoring and management purposes. Despite being a smallholder crop, rubber plantations are generally concentrated over large areas, which makes remote sensing a viable primary tool for mapping.

Another benefit is that most optical imagery data are free, comprehensive and easily accessible. We have observed that the application of remote sensing techniques in various subject areas identified in this study has expanded in line with the rise of zero-cost imagery (e.g., from Landsat and MODIS) because it reduces operational and research costs. Further, these imageries offer various spatial, spectral, and resolution specifications that can meet a diverse set of study objectives. The imagery data can be selected, filtered and downloaded at the user's convenience from an open-access website. This is particularly important for rubber smallholders, who often lack access to funding. However, to ensure that smallholders benefit from this, government agencies need to play a significant role in providing training, or in conducting research and sharing the findings with growers.

In addition, remote sensing enables the analysis of historical image data sets for up to 50 years, depending on the satellite. The long-term data archive from various sensors provides the advantage of long-term monitoring of rubber plantations. This is crucial, considering that rubber is a perennial crop that can last up to 30 years. Multi-temporal studies of specific events such as rubber disease incidents and weather anomalies can be conducted. Government agencies and relevant stakeholders can also conduct an assessment of rubber related policies over time, particularly those that relate to LULC.

The fourth benefit that should be highlighted is the ability to overcome constraints in obtaining rubber-related information. Relevant stakeholders can retrieve information such as rubber planting area and location by using the remote sensing approach. They no longer need to rely on information from smallholders in order to gather plantation data. This will improve data gathering methods and data quality [79].

Besides being a non-destructive method to gather information on rubber plantations, remote sensing data can also be analysed and interpreted for multiple purposes. There is a wide extent of information that can be gathered from either a single or set of remotely sensed image. In rubber plantations, this information may used in research activities that involves plantation mapping, stand age estimation, biomass and carbon estimation.

\subsection{Challenges}

There were several key challenges identified in the application of remote sensing to rubber plantings. First, the difficulty of obtaining cloud-free images is a major constraint because rubber plantations are primarily located in tropical areas. Tropical areas experience 
hot, humid weather and have a climate characterised by abundant rainfall, high humidity, and heavy cloud-cover conditions [119].

Second, rubber planting pixels are often misclassified as other land cover types [101], particularly because they are mainly located close to natural forests and other plantations. This has led to several inaccurate estimations of rubber planting areas. For instance, rubber was misclassified as forest in a study conducted in Northeastern Thailand [71]. This is because mature rubber trees possess similar spectral reflectance to forest and certain plantations $[29,113]$. Rubber was also mistakenly categorised as cropland, [59], oil palm in particular. Both share similar spectral characteristics and are cultivated in the same geographical areas [144]. However, characterising oil palm canopy using an object-based approach could minimise this problem.

It is also difficult to delineate rubber at different growth stages. The difficulties of separating rubber into several classes of stand ages are due to high intra-class variability [36]. This issue is further complicated by the presence of multiple clones in the plantations. Furthermore, younger rubber trees exhibit mixed spectral reflectance that emanates from a mixture of soil and other vegetation undergrowth [29]. Young or immature rubber plantations are also typically intercropped with rapidly growing cash crops such as maise, cocoa, cassava, and pineapple [62,145]. The young rubber trees have the spectral characteristics of open-canopy [111] where it only covers a small fraction of the planted area during the first five years of planting [36]. Thus, misclassification can arise due to a heterogeneous and complex mixture of land cover among these land features. Apart from the more general challenges inherent in the application of remote sensing, there is a critical question to be addressed - how can this technology be useful and practical for all relevant stakeholders, particularly rubber smallholders? While remote sensing may be affordable and feasible for researchers, managers, and rubber organisations, a lot more thought should go into how the technology can benefit smallholder farmers, who account for more than $85 \%$ of total global production [7]. In general, smallholders have limited financial access, possess low education levels, implement poor agricultural practices and have low adoption of new agricultural technology $[11,12,146,147]$. Therefore, relevant rubber organisations, private or government, will need to play an effective role to ensure that the technology is accessible. For example, these organisations can extract and analyse remote sensing data and disseminate their findings to smallholders through extension agents. A working framework would need to be developed so that smallholders can integrate the newly acquired information into their daily decision-making processes. As smallholders are the primary producers, this would benefit the industry as a whole.

\subsection{Future Potentials}

This section highlights and discusses four prospects for improving remote sensing rubber monitoring, based on the above-mentioned challenges. The identified prospects are the use of higher resolution data, algorithm enhancements, emerging processing platforms, and the application of remote sensing to less studied subject areas.

\subsubsection{Use of Higher Resolution Data}

The increasing trend of remote sensing data availability and accessibility has provided opportunities to improve its application to rubber studies. Landsat has proven to be the most widely used satellite data source in rubber tree studies, with almost 50 years of publicly accessible data.

The development of optical remote sensing is ongoing. The recent introduction of new sensors with improved spectral, spatial and temporal resolutions is providing richer datasets [148]. In 2015, several sensors were launched, including Sentinel-2A/B, and PlanetScope. These sensors have yet to be explored extensively in rubber tree monitoring. From selected documents in the review, only five reported the use of Sentinel-2 data for analysis $[71,81,87,132,133]$. At the time of this review, no studies have used image datasets from PlanetScope. 
Sentinel-2A/B data offer 13 spectral bands, which come with narrower bandwidths compared to other satellites. It is also the first satellite to provide three bands in the red edge spectrum range. The presence of these narrow spectral bandwidths could also improve the bio-physical estimation of rubber trees. For example, Band 5 of the Sentinel-2 satellite offers bandwidth between 697 and $711 \mathrm{~nm}$. It provides the capability to accurately capture leaf chlorophyll-a content, which peaks at $705 \mathrm{~nm}$. The chlorophyll-a is necessary for photosynthesis and is a measure of plant health [149]. In rubber, this information can be useful in monitoring rubber leaf disease outbreaks and facilitating the understanding of rubber phenology.

The higher spatial resolution provided by Sentinel-2 $(10 \mathrm{~m})$ and PlanetScope $(3 \mathrm{~m})$ may improve the accuracy and estimation of remote sensing outputs in monitoring rubber trees. The use of these sensors will reduce spatial variability, thus allowing precise information to be extracted from remote sensing derived indices and products. The adoption of these sensors in rubber studies can potentially address the misclassification and occurrence of high intra-class variability in rubber monitoring.

Furthermore, Sentinel-2 and PlanetScope offer high revisit frequency, at 5-day and daily frequencies, respectively. This high revisit frequency increases the opportunity to obtain more images. This is important for rubber studies as most rubber plantations are located in cloud-prone areas and high revisit frequency will improve the chances of obtaining clear images. Near real-time research on rubber tree monitoring could also be conducted.

Data from these satellites are also freely available, which could enable broader adoption by an industry that is often underfunded. The operationalisation of remote sensing in rubber, in this case, could be focused on the dissemination of information to smallholder farmers. Future research should look towards adopting freely available higher resolution images in order to overcome current challenges faced in the application of rubber studies.

Apart from satellites, unmanned aerial vehicles (UAV) have potential. Drones can provide detailed imagery, with pixel sizes in centimetres, due to operating at lower altitude. UAV can collect imagery under cloud cover and offer good flexibility in timing and frequency. Unfortunately, in rubber plantations, the application is bounded by several limitations. Tall rubber trees and large rubber plantations make the operation of drones challenging, particularly at the mature, closed canopy stage. More importantly, the affordability of this technology is a problem, as the rubber industry has suffered prolonged low rubber prices for almost a decade.

Future studies should also consider data fusion from multiple sensors (e.g., a combination of MODIS and Landsat). In this review, only ten documents, or $13.3 \%$ of the selected documents, used multiple sensors of different resolutions to achieve their set research objectives. Multisensor data fusion has received huge attention from researchers [150], and this has been boosted by the accessibility and availability of big remote sensing data. Data fusion involves a trade-off between the spatial and temporal resolution of satellite sensors. There are two categories of data fusion: Spatial-spectral fusion and spatial-temporal fusion. These result in finer spectral or temporal resolution data for analysis. Combining both datasets brings added value and knowledge to the remote sensing user [151]. It also improves the interpretation of data sources and is able to produce high-quality data representation [152]. This fusion technique could be useful for rubber planting land detection, recognition, identification and classification, and even for change detection at a plantation and leaf-level scale. The technology, in general, is considered to be a feasible and cost-effective way to obtain high-resolution data where it overcomes technology limitations and budget constraints [153-155].

In addition to this, the combination of imagery from passive and active sensors can provide different perspectives in order to better understand and evaluate rubber plantations, including the capability to overcome cloud cover issues in a study area. This kind of approach may elevate studies to the next level where stand age, biomass, carbon and disease detection can take place. Free-to-use active sensor data include RADARSAT. 
However, in this review, less than $10 \%$ (seven documents) of selected documents were found to integrate passive and active sensor data in their study.

\subsubsection{Algorithm Enhancements}

Another opportunity identified in this review is the adoption of machine learning in the algorithm and methods used for image classification. We observed a transition in the algorithm used in the selected studies. There was a clear move away from the classic classifiers used in the earlier studies to more advanced classifiers. Studies published earlier performed visual interpretations and pixel-based classifications, with a high number of studies applying the maximum likelihood classifier. More recent studies adopted advanced classifiers such as the Support Vector Machine, Random Forest and Decision Tree. These produced results with much higher accuracy than the classic classifiers. However, these advanced classifiers have yet to be thoroughly explored in the classification of rubber trees. Advanced classifiers deliver a sophisticated approach to feature extraction and multi-temporal classification [148]. They have the capability to handle a large amount of data, which is important in the era of big data. The adoption of these classifiers would be useful when hundreds to thousands of images need to be analysed for a study, particularly for global-scale rubber studies.

In addition to adopting the advanced classifiers, several studies have developed their own rubber phenology-based algorithms. These algorithms were designed to exploit rubber's unique foliation and refoliation characteristics. An improvement in classification results was achieved when these algorithms were adopted because they were able to overcome the difficulties in delineating rubber from other land use/cover types. The rubber phenology-based algorithms have demonstrated promise in accurately mapping and updating the spatial distribution of rubber plantations. We expect to see an increase in the use of self-developed and advanced algorithms in future rubber studies.

\subsubsection{Use of Emerging Processing Platforms}

With the advent of self-developed and more advanced algorithms, future studies will need access to high-performance computing resources for data processing. Several institutions (e.g., National Aeronautics and Space Administration (NASA) and the United States Geological Survey (USGS)) and company-based infrastructures (e.g., Google Earth Engine (GEE), the Amazon Web Services (AWS), the Copernicus Data and Information Access Services (DIAS)) have made significant efforts to meet this need, some of which are currently underway [156].

For example, GEE provides open-access satellite data and enables researchers to conduct analysis and to visualise geospatial datasets. Due to its capacity for handling large image datasets, and the availability of ready-to-run Javascript interfaces and active developer forums, this platform has seen an exponential increase in the number of users [157]. These processing platforms have diminished technological barriers, and eased data handling for large-scale studies, through cloud-based storage. At the time of this review, none of the included studies had taken advantage of the available processing platforms. Thus, future studies should consider using processing platforms when conducting rubber studies at a regional or global scale.

\subsubsection{Application in Less Studied Subject Areas}

Despite the promising progress in the application of remote sensing to monitoring rubber trees, several key areas were not comprehensively covered by the selected literature. This includes biomass and carbon estimation ( 9 out of 74 documents), leaf area index estimation ( 3 out of 74 documents), and disease detection ( 3 out of 74 documents). It is vital to have a comprehensive understanding of these topics because they reflect and influence the decisions of management, actors, and policymakers.

The advancement of remote sensing data, algorithms, and processing platforms will allow more detailed and precise mapping in order to monitor rubber trees. Since mapping 
is a fundamental step for any study, this is expected to indirectly increase the accuracy of biomass, carbon, and leaf area index estimation. There is also huge potential for rubber disease detection studies. Accurate mapping will provide data to assist in epidemiology studies and to control and manage disease outbreaks, in particular leaf diseases.

The recent outbreak of rubber leaf disease has created more opportunities for remote sensing studies in the area of rubber disease detection. As of December 2019, five countries were reported to have experienced Pestaliotiopsis leaf disease attack, with some plantations facing major outbreaks [40]. These countries are Indonesia, Malaysia, Sri Lanka, India and Thailand. The disease causes rubber tree leaves to fall and has affected large rubber plantation areas in these countries. Subsequently, latex production drops by up to $50 \%$. In the long run, this will impact an affected country's economy. More significantly for the rubber community, millions of smallholders will be impacted.

Remote sensing technology studies on current disease attacks can allow a comprehensive understanding of the disease outbreaks. Disease mapping, with remote sensing, can disclose disease locations on large scales of the affected areas. On the other hand, spread pattern analysis may help farmers and plantation managers to control disease spread, as well as projecting yield losses in real-time or into the future. This may lead to reduced chemical and pesticide use, reduced environmental impacts and lower production costs [158]. It may also enable better strategies for the control and prevention of disease in the future. Ultimately, there is significant potential for remote sensing to contribute to these less-studied subject areas.

\section{Conclusions}

This paper presents an overview of optical remote sensing applications to the study of rubber plantations. The selected studies have demonstrated the use of this technology in the management and monitoring of rubber plantations at various scales (e.g., regional, local, and canopy-leaf scale) and subject areas. The following points summarize the main finding of this review.

1. The number of studies keeps increasing partly due to the availability of remote sensing data over the years and the rubber boom in the mid-2000s. The majority of the selected studies are focused at a local scale with the most common study locations in Xishuangbanna and Hainan Island, China. Fewer studies were conducted in Southeast Asian countries, although there are a lot of major rubber producing countries in the region.

2. More studies at the regional scale using remote sensing should also be undertaken. It has now become more feasible given the enhancement of big data algorithms and emerging processing platforms.

3. Subject areas of mapping, change detection and stand age were extensively explored using several types of remote sensing data and classification algorithms. In contrast, for biomass, carbon and leaf area index estimation, most studies develop models to establish relationships between remote sensing data and these parameters. Examples of model inputs include spectral bands, vegetation indices and tree growth data.

4. Disease detection remains understudied but has the potential for growth. The use of remote sensing technology may benefit future studies on recent leaf fall disease outbreaks by examining changes in trees, understanding the spread pattern, estimating affected area, and predicting yield loss. The findings give greater control and support in monitoring and managing rubber plantations, especially for millions of smallholders.

5. The unique and outstanding rubber phenology characteristics have helped to delineate rubber from other land cover types and reduce misclassification error. Several recent documents have exploited this characteristic while performing classification, and some have developed phenology-based algorithm.

6. Expectedly, Landsat is the most frequently used optical sensor in the selected studies of this review. This is due to its long-term and free-cost availability. Future studies 
are suggested to consider using freely available high-resolution remote sensing data (e.g Sentinel-2, PlanetScope) and data fusion from multiple sensors with different resolutions in the study of monitoring rubber. Fewer studies have employed these types of data and demonstrated better accuracy than single-source remote sensing data studies.

In general, remote sensing plays a significant role in providing a deeper understanding of rubber management. The information retrieved through remote sensing images is vital for smallholders, plantation managers, and other decision-makers. Information on plantation expansion is also crucial in understanding the spatial extent and negative impacts of rubber expansion on the environment. Remote sensing data will support land management decisions and land use policies. Furthermore, the information retrieved from remotely sensed data has become a core indicator for monitoring plantation areas, observing biomass, assessing carbon stocks, and predicting yield gain or loss. Remote sensing is expected to continue play a growing and important role in managing global rubber production in the future.

Author Contributions: Conceptualisation, F.A.A. and I.S.A.; methodology, F.A.A. and A.M.K.; formal analysis, F.A.A.; data curation, F.A.A.; visualisation, F.A.A.; writing — original draft preparation, F.A.A.; writing - review and editing, A.M.K., I.S.A. and A.A.A. All authors have read and agreed to the published version of the manuscript.

Funding: This research received no external funding.

Institutional Review Board Statement: Not applicable.

Informed Consent Statement: Not applicable.

Data Availability Statement: The data presented in this study are available in Appendix A.

Acknowledgments: We thank the reviewers for their meticulous and insightful reviews that has helped improve the manuscript.

Conflicts of Interest: The authors declare no conflict of interest. 


\section{Appendix A}

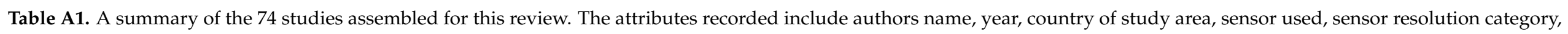

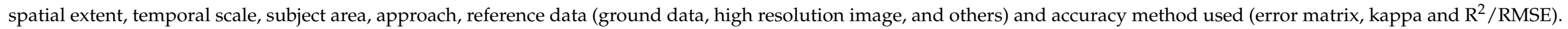
[Note: $\mathrm{Y}=$ yes and $\mathrm{N}=$ no.].

\begin{tabular}{|c|c|c|c|c|c|c|c|c|c|c|c|c|c|c|c|c|}
\hline \multirow[b]{2}{*}{ No } & \multirow[b]{2}{*}{ Authors } & \multirow[b]{2}{*}{ Ref } & \multirow[b]{2}{*}{ Year } & \multirow[b]{2}{*}{ Country } & \multirow[b]{2}{*}{ Sensor } & \multirow[b]{2}{*}{$\begin{array}{c}\text { Sensor } \\
\text { Resolution }\end{array}$} & \multirow[b]{2}{*}{$\begin{array}{c}\text { Spatial } \\
\text { Extent }\end{array}$} & \multirow[b]{2}{*}{$\begin{array}{c}\text { Temporal } \\
\text { Scale }\end{array}$} & \multirow[b]{2}{*}{$\begin{array}{l}\text { Subject } \\
\text { Area }\end{array}$} & \multirow[b]{2}{*}{ Approach } & \multicolumn{3}{|c|}{ Reference Data } & \multicolumn{3}{|c|}{ Accuracy Method } \\
\hline & & & & & & & & & & & $\begin{array}{c}\text { Ground } \\
\text { Data }\end{array}$ & $\begin{array}{c}\text { High } \\
\text { Resolution } \\
\text { Image }\end{array}$ & Others & $\begin{array}{c}\text { Error } \\
\text { Matrix }\end{array}$ & Kappa & $\mathbf{R}^{2} / \mathrm{RMSE}$ \\
\hline 1 & Rao et al. & [38] & 2003 & India & IRS & Medium & Local & Multi-temporal & Mapping & Land cover & $\mathrm{Y}$ & $\mathrm{N}$ & $\mathrm{N}$ & $\mathrm{N}$ & $\mathrm{N}$ & $\mathrm{N}$ \\
\hline 2 & Suratman & [18] & 2003 & Malaysia & Landsat TM & Medium & Local & Uni-temporal & Mapping & Land cover & $\mathrm{N}$ & $\mathrm{N}$ & $\mathrm{Y}$ & $\mathrm{Y}$ & $\mathrm{Y}$ & $\mathrm{N}$ \\
\hline 3 & $\begin{array}{l}\text { Suratman } \\
\text { et al. }\end{array}$ & [67] & 2005 & Malaysia & Landsat TM & Medium & Local & Uni-temporal & Mapping & Statistical model & $\mathrm{Y}$ & $\mathrm{N}$ & $\mathrm{Y}$ & $\mathrm{Y}$ & $\mathrm{N}$ & $\mathrm{N}$ \\
\hline 4 & Meti et al. & [65] & 2008 & India & LISS III & Medium & Local & Uni-temporal & Mapping & Land cover & $\mathrm{N}$ & $\mathrm{N}$ & $\mathrm{N}$ & $\mathrm{Y}$ & $\mathrm{Y}$ & $\mathrm{N}$ \\
\hline 5 & Li \& Fox & [68] & 2011 & $\begin{array}{l}\text { Thailand, Laos, } \\
\text { China }\end{array}$ & ASTER & Medium & Regional & Uni-temporal & Mapping & Land cover & Y & Y & $\mathrm{N}$ & Y & Y & $\mathrm{Y}$ \\
\hline 6 & Li \& Fox & [36] & 2012 & $\begin{array}{c}\text { China, Myanmar, } \\
\text { Laos, Thailand, } \\
\text { Vietnam, Cambodia }\end{array}$ & MODIS & Low & Regional & Multi-temporal & Mapping & Land cover & $\mathrm{N}$ & $\mathrm{Y}$ & $\mathrm{Y}$ & $\mathrm{Y}$ & Y & $\mathrm{N}$ \\
\hline 7 & Dong et al. & [72] & 2013 & China & $\begin{array}{l}\text { Landsat TM, } \\
\text { Landsat 7, } \\
\text { PALSAR }\end{array}$ & $\begin{array}{c}\text { Low + } \\
\text { Medium }\end{array}$ & Local & Multi-temporal & Mapping & $\begin{array}{l}\text { Phenology-based } \\
\text { Algorithm }\end{array}$ & $\mathrm{Y}$ & $\mathrm{Y}$ & Y & $\mathrm{Y}$ & $\mathrm{Y}$ & $\mathrm{N}$ \\
\hline 8 & $\begin{array}{l}\text { Shidiq } \\
\text { et al. }\end{array}$ & [69] & 2014 & Malaysia & Landsat TM & Medium & Local & Multi-temporal & Mapping & Land cover & $\mathrm{N}$ & $\mathrm{N}$ & Y & Y & $\mathrm{Y}$ & $\mathrm{N}$ \\
\hline 9 & Dai et al. & [73] & 2014 & China & Landsat TM & Medium & Local & Uni-temporal & Mapping & Land cover & $\mathrm{Y}$ & $\mathrm{Y}$ & $\mathrm{N}$ & $Y$ & $\mathrm{Y}$ & $\mathrm{N}$ \\
\hline 11 & Fan et al. & [39] & 2015 & China & Landsat 8 & Medium & Local & Multi-temporal & Mapping & $\begin{array}{l}\text { Phenology-based } \\
\text { Algorithm }\end{array}$ & $\mathrm{Y}$ & Y & $\mathrm{N}$ & $\mathrm{Y}$ & Y & $\mathrm{N}$ \\
\hline 12 & $\begin{array}{c}\text { Abd } \\
\text { Razak } \\
\text { et al. }\end{array}$ & [59] & 2017 & Malaysia & $\begin{array}{l}\text { Landsat TM, } \\
\text { Landsat 7, } \\
\text { Landsat } 8 \\
\end{array}$ & Medium & Local & Multi-temporal & Mapping & Land cover & $\mathrm{N}$ & $\mathrm{Y}$ & $\mathrm{N}$ & Y & $\mathrm{Y}$ & $\mathrm{N}$ \\
\hline 13 & Dibs et al. & [29] & 2017 & Malaysia & SPOT-5 & Medium & Local & Uni-temporal & Mapping & Land cover & $\mathrm{Y}$ & $\mathrm{N}$ & $\mathrm{N}$ & $\mathrm{Y}$ & $\mathrm{Y}$ & $\mathrm{N}$ \\
\hline 14 & $\begin{array}{l}\text { Pradeep } \\
\text { et al. }\end{array}$ & [75] & 2017 & India & IRS & Medium & Local & Uni-temporal & Mapping & Land cover & $\mathrm{Y}$ & $\mathrm{N}$ & Y & $\mathrm{Y}$ & $\mathrm{N}$ & $\mathrm{N}$ \\
\hline 15 & $\begin{array}{l}\text { Shidiq } \\
\text { et al. }\end{array}$ & [70] & 2017 & Malaysia & $\begin{array}{l}\text { Landsat 5, } \\
\text { PALSAR }\end{array}$ & Medium & Local & Uni-temporal & Mapping & Land cover & Y & $\mathrm{N}$ & $\mathrm{N}$ & $\mathrm{Y}$ & $\mathrm{Y}$ & $\mathrm{N}$ \\
\hline 16 & Han et al. & {$[58]$} & 2018 & China & Landsat 8 & Medium & Local & Multi-temporal & Mapping & Land cover & $\mathrm{Y}$ & $\mathrm{Y}$ & $\mathrm{N}$ & $\mathrm{Y}$ & $\mathrm{Y}$ & $\mathrm{N}$ \\
\hline
\end{tabular}


Table A1. Cont.

\begin{tabular}{|c|c|c|c|c|c|c|c|c|c|c|c|c|c|c|c|c|}
\hline \multirow[b]{2}{*}{ No } & \multirow[b]{2}{*}{ Authors } & \multirow[b]{2}{*}{ Ref } & \multirow[b]{2}{*}{ Year } & \multirow[b]{2}{*}{ Country } & \multirow[b]{2}{*}{ Sensor } & \multirow[b]{2}{*}{$\begin{array}{c}\text { Sensor } \\
\text { Resolution }\end{array}$} & \multirow[b]{2}{*}{$\begin{array}{c}\text { Spatial } \\
\text { Extent }\end{array}$} & \multirow[b]{2}{*}{$\begin{array}{c}\text { Temporal } \\
\text { Scale }\end{array}$} & \multirow[b]{2}{*}{$\begin{array}{l}\text { Subject } \\
\text { Area }\end{array}$} & \multirow[b]{2}{*}{ Approach } & \multicolumn{3}{|c|}{ Reference Data } & \multicolumn{3}{|c|}{ Accuracy Method } \\
\hline & & & & & & & & & & & $\begin{array}{l}\text { Ground } \\
\text { Data }\end{array}$ & $\begin{array}{c}\text { High } \\
\text { Resolution } \\
\text { Image }\end{array}$ & Others & $\begin{array}{c}\text { Error } \\
\text { Matrix }\end{array}$ & Kappa & $\mathrm{R}^{2} / \mathrm{RMSE}$ \\
\hline 17 & Zhai et al. & {$[76]$} & 2018 & China & $\begin{array}{l}\text { MODIS, } \\
\text { Landsat 5, } \\
\text { Landsat 7, } \\
\text { PALSAR }\end{array}$ & Low+ Medium & Local & Multi-temporal & Mapping & $\begin{array}{l}\text { Phenology-based } \\
\text { Algorithm }\end{array}$ & $\mathrm{Y}$ & Y & $\mathrm{N}$ & Y & $\mathrm{Y}$ & $\mathrm{N}$ \\
\hline 18 & Gao et al. & {$[31]$} & 2019 & China & $\begin{array}{c}\text { MODIS, } \\
\text { Landsat TM, } \\
\text { Landsat 7, } \\
\text { Landsat } 8\end{array}$ & $\begin{array}{c}\text { Low }+ \\
\text { Medium }\end{array}$ & Local & Multi-temporal & Mapping & Land cover & $\mathrm{Y}$ & Y & $\mathrm{N}$ & $\mathrm{Y}$ & Y & $\mathrm{N}$ \\
\hline 19 & Xiao et al. & {$[77]$} & 2019 & China & Landsat 8 & Medium & Local & Uni-temporal & Mapping & $\begin{array}{l}\text { Phenology-based } \\
\text { Algorithm }\end{array}$ & Y & Y & $\mathrm{N}$ & $\mathrm{Y}$ & Y & $\mathrm{N}$ \\
\hline 20 & Xiao et al. & {$[78]$} & 2019 & China & Landsat 8 & Medium & Local & Multi-temporal & Mapping & $\begin{array}{c}\text { Phenology-based } \\
\text { Algorithm }\end{array}$ & $\mathrm{Y}$ & Y & $\mathrm{N}$ & $\mathrm{Y}$ & $\mathrm{Y}$ & $\mathrm{N}$ \\
\hline 21 & $\begin{array}{l}\text { Hazir \& } \\
\text { Muda }\end{array}$ & [79] & 2020 & Malaysia & Landsat 8 & Medium & Local & Multi-temporal & Mapping & Land cover & $Y$ & $\mathrm{~N}$ & $\mathrm{~N}$ & $\mathrm{Y}$ & $\mathrm{N}$ & $\mathrm{N}$ \\
\hline 22 & Xiao et al. & {$[80]$} & 2020 & Laos & Sentinel-2 & High & Local & Multi-temporal & Mapping & $\begin{array}{l}\text { Phenology-based } \\
\text { Algorithm }\end{array}$ & $\mathrm{Y}$ & $\mathrm{Y}$ & $\mathrm{N}$ & $\mathrm{Y}$ & $\mathrm{Y}$ & $\mathrm{N}$ \\
\hline 23 & Xiao et al. & {$[81]$} & 2020 & Laos & Landsat 8 & Medium & Local & Multi-temporal & Mapping & $\begin{array}{l}\text { Phenology-based } \\
\text { Algorithm }\end{array}$ & Y & Y & Y & $\mathrm{Y}$ & Y & $\mathrm{N}$ \\
\hline 25 & Liu et al. & [89] & 2006 & China & $\begin{array}{l}\text { Landsat TM, } \\
\text { Landsat } 7\end{array}$ & Medium & Local & Multi-temporal & $\begin{array}{l}\text { Change } \\
\text { Detec- } \\
\text { tion }\end{array}$ & $\begin{array}{l}\text { Land use/land } \\
\text { cover change }\end{array}$ & $\mathrm{Y}$ & $\mathrm{Y}$ & $\mathrm{Y}$ & Y & $\mathrm{N}$ & $\mathrm{N}$ \\
\hline 26 & Suratman & {$[64]$} & 2007 & Selangor & Landsat TM & Medium & Local & Multi-temporal & $\begin{array}{c}\text { Change } \\
\text { Detec- } \\
\text { tion }\end{array}$ & $\begin{array}{l}\text { Land use/land } \\
\text { cover change }\end{array}$ & $\mathrm{Y}$ & $\mathrm{N}$ & $\mathrm{Y}$ & $\mathrm{N}$ & $\mathrm{N}$ & $\mathrm{N}$ \\
\hline 27 & H. Li et al. & {$[94]$} & 2007 & China & $\begin{array}{l}\text { Landsat MSS, } \\
\text { Landsat TM, } \\
\text { Landsat 7 }\end{array}$ & Medium & Local & Multi-temporal & $\begin{array}{l}\text { Change } \\
\text { Detec- } \\
\text { tion }\end{array}$ & $\begin{array}{l}\text { Land use/land } \\
\text { cover change }\end{array}$ & $\mathrm{Y}$ & $\mathrm{N}$ & $\mathrm{Y}$ & $\mathrm{Y}$ & $\mathrm{N}$ & $\mathrm{N}$ \\
\hline 28 & $\begin{array}{l}\text { Pensuk \& } \\
\text { Shrestha }\end{array}$ & {$[57]$} & 2008 & Thailand & $\begin{array}{l}\text { Landsat MSS, } \\
\text { Landsat TM, } \\
\text { Landsat 7 }\end{array}$ & Medium & Local & Multi-temporal & $\begin{array}{c}\text { Change } \\
\text { Detec- } \\
\text { tion }\end{array}$ & $\begin{array}{l}\text { Land use/land } \\
\text { cover change }\end{array}$ & $\mathrm{Y}$ & $\mathrm{N}$ & $\mathrm{N}$ & $\mathrm{N}$ & $\mathrm{N}$ & $\mathrm{N}$ \\
\hline 29 & $\begin{array}{l}\text { Vadjunec } \\
\text { et al. }\end{array}$ & [100] & 2009 & Brazil & $\begin{array}{l}\text { Landsat TM, } \\
\text { Landsat } 7\end{array}$ & Medium & Local & Multi-temporal & $\begin{array}{c}\text { Change } \\
\text { Detec- } \\
\text { tion }\end{array}$ & $\begin{array}{l}\text { Land use/land } \\
\text { cover change }\end{array}$ & $\mathrm{Y}$ & $\mathrm{N}$ & $\mathrm{N}$ & $\mathrm{Y}$ & $\mathrm{N}$ & $\mathrm{N}$ \\
\hline 30 & $\begin{array}{l}\text { Ekadinata } \\
\text { \& Vincent }\end{array}$ & [101] & 2011 & Indonesia & $\begin{array}{l}\text { Landsat MSS, } \\
\text { Landsat TM, } \\
\text { Landsat 7 }\end{array}$ & Medium & Local & Multi-temporal & $\begin{array}{c}\text { Change } \\
\text { Detec- } \\
\text { tion }\end{array}$ & $\begin{array}{l}\text { Land use/land } \\
\text { cover change }\end{array}$ & $\mathrm{Y}$ & $\mathrm{N}$ & $\mathrm{N}$ & $\mathrm{Y}$ & $\mathrm{N}$ & $\mathrm{N}$ \\
\hline
\end{tabular}


Table A1. Cont.

\begin{tabular}{|c|c|c|c|c|c|c|c|c|c|c|c|c|c|c|c|c|}
\hline \multirow[b]{2}{*}{ No } & \multirow[b]{2}{*}{ Authors } & \multirow[b]{2}{*}{ Ref } & \multirow[b]{2}{*}{ Year } & \multirow[b]{2}{*}{ Country } & \multirow[b]{2}{*}{ Sensor } & \multirow[b]{2}{*}{$\begin{array}{c}\text { Sensor } \\
\text { Resolution }\end{array}$} & \multirow[b]{2}{*}{$\begin{array}{c}\text { Spatial } \\
\text { Extent }\end{array}$} & \multirow[b]{2}{*}{$\begin{array}{c}\text { Temporal } \\
\text { Scale }\end{array}$} & \multirow[b]{2}{*}{$\begin{array}{l}\text { Subject } \\
\text { Area }\end{array}$} & \multirow[b]{2}{*}{ Approach } & \multicolumn{3}{|c|}{ Reference Data } & \multicolumn{3}{|c|}{ Accuracy Method } \\
\hline & & & & & & & & & & & $\begin{array}{l}\text { Ground } \\
\text { Data }\end{array}$ & $\begin{array}{c}\text { High } \\
\text { Resolution } \\
\text { Image }\end{array}$ & Others & $\begin{array}{c}\text { Error } \\
\text { Matrix }\end{array}$ & Kappa & $\mathbf{R}^{2} / \mathrm{RMSE}$ \\
\hline 32 & $\begin{array}{l}\text { Xiaona } \\
\text { Liu et al. }\end{array}$ & {$[32]$} & 2013 & $\begin{array}{l}\text { China, Laos, } \\
\text { Myanmar }\end{array}$ & $\begin{array}{c}\text { Landsat MSS, } \\
\text { Landsat TM, } \\
\text { Landsat 7, } \\
\text { MODIS }\end{array}$ & Low + Medium & Regional & Multi-temporal & $\begin{array}{l}\text { Change } \\
\text { Detec- } \\
\text { tion }\end{array}$ & $\begin{array}{l}\text { Land use/land } \\
\text { cover change }\end{array}$ & $\mathrm{Y}$ & $\mathrm{N}$ & $\mathrm{Y}$ & Y & $\mathrm{N}$ & $\mathrm{N}$ \\
\hline 33 & $\begin{array}{l}\text { Phompila } \\
\text { et al. }\end{array}$ & [103] & 2014 & Laos & Landsat 7 & Medium & Local & Multi-temporal & $\begin{array}{l}\text { Change } \\
\text { Detec- } \\
\text { tion }\end{array}$ & $\begin{array}{l}\text { Land use/land } \\
\text { cover change }\end{array}$ & $\mathrm{Y}$ & $\mathrm{Y}$ & $\mathrm{N}$ & $\mathrm{Y}$ & $\mathrm{N}$ & $\mathrm{N}$ \\
\hline 35 & $\begin{array}{l}\text { H. Chen } \\
\text { et al. }\end{array}$ & {$[85]$} & 2016 & China & $\begin{array}{l}\text { Landsat TM, } \\
\text { Landsat 7, } \\
\text { RapidEye }\end{array}$ & $\begin{array}{c}\text { Medium }+ \\
\text { High }\end{array}$ & Local & Multi-temporal & $\begin{array}{l}\text { Change } \\
\text { Detec- } \\
\text { tion }\end{array}$ & $\begin{array}{l}\text { Land use/land } \\
\text { cover change }\end{array}$ & $\mathrm{Y}$ & Y & $\mathrm{N}$ & Y & Y & $\mathrm{N}$ \\
\hline 36 & $\begin{array}{l}\text { X. Liu } \\
\text { et al. }\end{array}$ & {$[97]$} & 2016 & Laos, China & $\begin{array}{l}\text { Landsat TM, } \\
\text { Landsat } 7\end{array}$ & Medium & Regional & Multi-temporal & $\begin{array}{l}\text { Change } \\
\text { Detec- } \\
\text { tion }\end{array}$ & $\begin{array}{l}\text { Land use/land } \\
\text { cover change }\end{array}$ & $\mathrm{Y}$ & $\mathrm{N}$ & $\mathrm{N}$ & $\mathrm{Y}$ & $\mathrm{N}$ & $\mathrm{N}$ \\
\hline 37 & Sun et al. & {$[62]$} & 2017 & China & $\begin{array}{c}\text { Landsat TM, } \\
\text { Landsat 7, } \\
\text { Landsat } 8\end{array}$ & Medium & Local & Multi-temporal & $\begin{array}{l}\text { Change } \\
\text { Detec- } \\
\text { tion }\end{array}$ & $\begin{array}{l}\text { Land use/land } \\
\text { cover change }\end{array}$ & $\mathrm{Y}$ & Y & $\mathrm{N}$ & Y & $\mathrm{Y}$ & $\mathrm{N}$ \\
\hline 39 & $\begin{array}{l}\text { Chakraborty } \\
\text { et al. }\end{array}$ & {$[63]$} & 2018 & India & LISS III & Medium & Local & Multi-temporal & $\begin{array}{c}\text { Change } \\
\text { Detec- } \\
\text { tion }\end{array}$ & $\begin{array}{l}\text { Land use/land } \\
\text { cover change }\end{array}$ & Y & $\mathrm{N}$ & $\mathrm{N}$ & $\mathrm{N}$ & $\mathrm{N}$ & $\mathrm{N}$ \\
\hline 40 & $\begin{array}{l}\text { Özdoğan } \\
\text { et al. }\end{array}$ & {$[96]$} & 2018 & Laos & $\begin{array}{l}\text { Landsat TM, } \\
\text { Landsat } 7\end{array}$ & Medium & Local & Multi-temporal & $\begin{array}{c}\text { Change } \\
\text { Detec- } \\
\text { tion }\end{array}$ & $\begin{array}{l}\text { Land use/land } \\
\text { cover change }\end{array}$ & Y & $\mathrm{N}$ & $\mathrm{N}$ & $\mathrm{Y}$ & $\mathrm{N}$ & $\mathrm{N}$ \\
\hline 41 & Kou et al. & {$[98]$} & 2018 & China & $\begin{array}{l}\text { MODIS, } \\
\text { Landsat 5, } \\
\text { Landsat 7, } \\
\text { PALSAR }\end{array}$ & Medium & Local & Multi-temporal & $\begin{array}{l}\text { Change } \\
\text { Detec- } \\
\text { tion }\end{array}$ & $\begin{array}{l}\text { Land use/land } \\
\text { cover change }\end{array}$ & $\mathrm{Y}$ & $\mathrm{Y}$ & $\mathrm{Y}$ & $\mathrm{Y}$ & $\mathrm{N}$ & $\mathrm{N}$ \\
\hline 42 & $\begin{array}{l}\text { Grogan } \\
\text { et al. }\end{array}$ & {$[87]$} & 2019 & Cambodia & $\begin{array}{c}\text { MODIS, } \\
\text { Landsat TM, } \\
\text { Landsat 7, } \\
\text { Landsat8, } \\
\text { Sentinel-2 }\end{array}$ & $\begin{array}{l}\text { Low + Medium } \\
+ \text { High }\end{array}$ & Local & Multi-temporal & $\begin{array}{l}\text { Change } \\
\text { Detec- } \\
\text { tion }\end{array}$ & $\begin{array}{l}\text { Land use/land } \\
\text { cover change }\end{array}$ & $\mathrm{N}$ & $\mathrm{Y}$ & $\mathrm{N}$ & $\mathrm{Y}$ & $\mathrm{N}$ & $\mathrm{N}$ \\
\hline 43 & Xiao et al. & {$[53]$} & 2019 & China & $\begin{array}{c}\text { Landsat TM, } \\
\text { Landsat 7, } \\
\text { Landsat } 8\end{array}$ & Medium & Local & Multi-temporal & $\begin{array}{l}\text { Change } \\
\text { Detec- } \\
\text { tion }\end{array}$ & $\begin{array}{l}\text { Land use/land } \\
\text { cover change }\end{array}$ & $\mathrm{Y}$ & $\mathrm{Y}$ & $\mathrm{N}$ & Y & Y & $\mathrm{N}$ \\
\hline
\end{tabular}


Table A1. Cont.

\begin{tabular}{|c|c|c|c|c|c|c|c|c|c|c|c|c|c|c|c|c|}
\hline \multirow[b]{2}{*}{ No } & \multirow[b]{2}{*}{ Authors } & \multirow[b]{2}{*}{ Ref } & \multirow[b]{2}{*}{ Year } & \multirow[b]{2}{*}{ Country } & \multirow[b]{2}{*}{ Sensor } & \multirow[b]{2}{*}{$\begin{array}{c}\text { Sensor } \\
\text { Resolution }\end{array}$} & \multirow[b]{2}{*}{$\begin{array}{l}\text { Spatial } \\
\text { Extent }\end{array}$} & \multirow[b]{2}{*}{$\begin{array}{c}\text { Temporal } \\
\text { Scale }\end{array}$} & \multirow[b]{2}{*}{$\begin{array}{l}\text { Subject } \\
\text { Area }\end{array}$} & \multirow[b]{2}{*}{ Approach } & \multicolumn{3}{|c|}{ Reference Data } & \multicolumn{3}{|c|}{ Accuracy Method } \\
\hline & & & & & & & & & & & $\begin{array}{c}\text { Ground } \\
\text { Data }\end{array}$ & $\begin{array}{c}\text { High } \\
\text { Resolution } \\
\text { Image }\end{array}$ & Others & $\begin{array}{c}\text { Error } \\
\text { Matrix }\end{array}$ & Kappa & $\mathrm{R}^{2} / \mathrm{RMSE}$ \\
\hline 44 & Xiao et al. & {$[84]$} & 2019 & China & $\begin{array}{l}\text { Landsat TM, } \\
\text { Landsat 7, } \\
\text { Landsat } 8\end{array}$ & Medium & Local & Multi-temporal & $\begin{array}{l}\text { Change } \\
\text { Detec- } \\
\text { tion }\end{array}$ & $\begin{array}{l}\text { Land use/land } \\
\text { cover change }\end{array}$ & Y & $\mathrm{Y}$ & Y & $\mathrm{Y}$ & Y & $\mathrm{N}$ \\
\hline 45 & $\begin{array}{c}\text { Suratman } \\
\text { et al. }\end{array}$ & {$[108]$} & 2004 & Malaysia & Landsat TM & Medium & Local & Uni-temporal & $\begin{array}{c}\text { Stand } \\
\text { Age }\end{array}$ & Statistical Model & $\mathrm{Y}$ & $\mathrm{N}$ & $\mathrm{Y}$ & Y & $\mathrm{N}$ & $\mathrm{Y}$ \\
\hline 46 & $\begin{array}{l}\text { Mongkolsawa } \\
\text { et al. }\end{array}$ & $\mathrm{at}_{[112]}$ & 2010 & Thailand & $\begin{array}{l}\text { SPOT-2, } \\
\text { SPOT-4, } \\
\text { SPOT-5, } \\
\text { THEOS }\end{array}$ & Medium & Local & Uni-temporal & $\begin{array}{l}\text { Stand } \\
\text { Age }\end{array}$ & $\begin{array}{c}\text { Image } \\
\text { Classification }\end{array}$ & $\mathrm{Y}$ & $\mathrm{N}$ & $\mathrm{Y}$ & $\mathrm{Y}$ & Y & $\mathrm{N}$ \\
\hline 47 & Li \& Fox & [113] & 2011 & Thailand & Landsat TM & Medium & Local & Uni-temporal & $\begin{array}{c}\text { Stand } \\
\text { Age }\end{array}$ & $\begin{array}{c}\text { Image } \\
\text { Classification }\end{array}$ & $\mathrm{N}$ & $\mathrm{N}$ & $\mathrm{Y}$ & $\mathrm{N}$ & $\mathrm{N}$ & $\mathrm{Y}$ \\
\hline 48 & $\begin{array}{l}\text { Putklang } \\
\text { et al. }\end{array}$ & {$[86]$} & 2012 & Thailand & THEOS & Medium & Local & Uni-temporal & $\begin{array}{c}\text { Stand } \\
\text { Age }\end{array}$ & $\begin{array}{c}\text { Image } \\
\text { Classification }\end{array}$ & $\mathrm{Y}$ & $\mathrm{N}$ & $\mathrm{N}$ & $\mathrm{N}$ & Y & $\mathrm{N}$ \\
\hline 49 & Chen et al. & [110] & 2012 & China & Landsat TM & Medium & Local & Uni-temporal & $\begin{array}{l}\text { Stand } \\
\text { Age }\end{array}$ & Statistical Model & $\mathrm{N}$ & $\mathrm{N}$ & $\mathrm{N}$ & $\mathrm{N}$ & $\mathrm{N}$ & $\mathrm{Y}$ \\
\hline 50 & $\begin{array}{l}\text { Koedsin \& } \\
\text { Huete }\end{array}$ & [114] & 2015 & Thailand & Pléiades & Very High & Local & Uni-temporal & $\begin{array}{l}\text { Stand } \\
\text { Age }\end{array}$ & $\begin{array}{c}\text { Image } \\
\text { Classification }\end{array}$ & $\mathrm{N}$ & $\mathrm{Y}$ & $\mathrm{Y}$ & Y & $\mathrm{Y}$ & $\mathrm{N}$ \\
\hline 52 & Kou et al. & [119] & 2015 & China & $\begin{array}{l}\text { Landsat TM, } \\
\text { Landsat 7, } \\
\text { PALSAR }\end{array}$ & Medium & Local & Multi-temporal & $\begin{array}{l}\text { Stand } \\
\text { Age }\end{array}$ & $\begin{array}{l}\text { Land Use Land } \\
\text { Cover (LULC) } \\
\text { Detection }\end{array}$ & $\mathrm{Y}$ & Y & $\mathrm{N}$ & $\mathrm{Y}$ & Y & $\mathrm{N}$ \\
\hline 53 & $\begin{array}{l}\text { Shidiq \& } \\
\text { Ismail }\end{array}$ & [109] & 2016 & Malaysia & Landsat 8 & Medium & Local & Uni-temporal & $\begin{array}{c}\text { Stand } \\
\text { Age }\end{array}$ & Statistical Model & $\mathrm{Y}$ & $\mathrm{N}$ & $\mathrm{N}$ & $\mathrm{N}$ & $\mathrm{N}$ & $\mathrm{Y}$ \\
\hline 54 & Beckschäfer & {$[117]$} & 2017 & China & $\begin{array}{l}\text { Landsat TM, } \\
\text { Landsat } 7\end{array}$ & Medium & Local & Multi-temporal & $\begin{array}{l}\text { Stand } \\
\text { Age }\end{array}$ & $\begin{array}{l}\text { Land Use Land } \\
\text { Cover (LULC) } \\
\text { Detection }\end{array}$ & $\mathrm{N}$ & Y & $\mathrm{N}$ & $\mathrm{Y}$ & $\mathrm{N}$ & $\mathrm{N}$ \\
\hline 55 & $\begin{array}{l}\text { Kaewplang } \\
\text { \& Srihanu }\end{array}$ & [55] & 2017 & Thailand & EO-1 Hyperion & High & Local & Uni-temporal & $\begin{array}{l}\text { Stand } \\
\text { Age }\end{array}$ & Statistical Model & $\mathrm{Y}$ & $\mathrm{N}$ & $\mathrm{N}$ & $\mathrm{N}$ & $\mathrm{N}$ & $\mathrm{Y}$ \\
\hline 56 & $\begin{array}{l}\text { G. Chen } \\
\text { et al. }\end{array}$ & [111] & 2018 & $\begin{array}{l}\text { China, Myanmar, } \\
\text { Laos }\end{array}$ & $\begin{array}{l}\text { Landsat TM, } \\
\text { Landsat 7, } \\
\text { Landsat } 8\end{array}$ & Medium & Regional & Multi-temporal & $\begin{array}{l}\text { Stand } \\
\text { Age }\end{array}$ & Statistical Model & $\mathrm{N}$ & $\mathrm{Y}$ & $\mathrm{N}$ & $\mathrm{Y}$ & Y & $\mathrm{N}$ \\
\hline 57 & Chen et 11. & {$[107]$} & 2018 & China & $\begin{array}{c}\text { Landsat TM, } \\
\text { Landsat 7, } \\
\text { Landsat 8, } \\
\text { PALSAR }\end{array}$ & Medium & Local & Multi-temporal & $\begin{array}{l}\text { Stand } \\
\text { Age }\end{array}$ & $\begin{array}{l}\text { Land Use Land } \\
\text { Cover (LULC) } \\
\text { Detection }\end{array}$ & $\mathrm{Y}$ & Y & $\mathrm{N}$ & $\mathrm{Y}$ & $\mathrm{N}$ & $\mathrm{N}$ \\
\hline 58 & Xiao et al. & {$[118]$} & 2019 & China & $\begin{array}{l}\text { Landsat TM, } \\
\text { Landsat 7, } \\
\text { Landsat } 8\end{array}$ & Medium & Local & Multi-temporal & $\begin{array}{l}\text { Stand } \\
\text { Age }\end{array}$ & $\begin{array}{l}\text { Land Use Land } \\
\text { Cover (LULC) } \\
\text { Detection }\end{array}$ & $\mathrm{Y}$ & $\mathrm{N}$ & $\mathrm{N}$ & $\mathrm{Y}$ & $\mathrm{Y}$ & $\mathrm{N}$ \\
\hline
\end{tabular}


Table A1. Cont.

\begin{tabular}{|c|c|c|c|c|c|c|c|c|c|c|c|c|c|c|c|c|}
\hline \multirow[b]{2}{*}{ No } & \multirow[b]{2}{*}{ Authors } & \multirow[b]{2}{*}{ Ref } & \multirow[b]{2}{*}{ Year } & \multirow[b]{2}{*}{ Country } & \multirow[b]{2}{*}{ Sensor } & \multirow[b]{2}{*}{$\begin{array}{c}\text { Sensor } \\
\text { Resolution }\end{array}$} & \multirow[b]{2}{*}{$\begin{array}{c}\text { Spatial } \\
\text { Extent }\end{array}$} & \multirow[b]{2}{*}{$\begin{array}{c}\text { Temporal } \\
\text { Scale }\end{array}$} & \multirow[b]{2}{*}{$\begin{array}{c}\text { Subject } \\
\text { Area }\end{array}$} & \multirow[b]{2}{*}{ Approach } & \multicolumn{3}{|c|}{ Reference Data } & \multicolumn{3}{|c|}{ Accuracy Method } \\
\hline & & & & & & & & & & & $\begin{array}{c}\text { Ground } \\
\text { Data }\end{array}$ & $\begin{array}{c}\text { High } \\
\text { Resolution } \\
\text { Image }\end{array}$ & Others & $\begin{array}{c}\text { Error } \\
\text { Matrix }\end{array}$ & Kappa & $\mathrm{R}^{2} / \mathrm{RMSE}$ \\
\hline 59 & $\begin{array}{l}\text { Somching } \\
\text { et al. }\end{array}$ & [116] & 2020 & Thailand & $\begin{array}{l}\text { Landsat TM, } \\
\text { Landsat 7, } \\
\text { Landsat } 8\end{array}$ & Medium & Local & Multi-temporal & $\begin{array}{l}\text { Stand } \\
\text { Age }\end{array}$ & $\begin{array}{l}\text { Image } \\
\text { Classification }\end{array}$ & $\mathrm{N}$ & Y & $\mathrm{Y}$ & $\mathrm{Y}$ & $\mathrm{N}$ & $\mathrm{N}$ \\
\hline 60 & $\begin{array}{l}\text { Suratman } \\
\text { et al. }\end{array}$ & [49] & 2002 & Malaysia & Landsat TM & Medium & Local & Uni-temporal & $\begin{array}{c}\text { Biomass } \\
\text { and } \\
\text { Carbon }\end{array}$ & Statistical model & $\mathrm{Y}$ & $\mathrm{N}$ & $\mathrm{N}$ & $\mathrm{Y}$ & $\mathrm{N}$ & $\mathrm{Y}$ \\
\hline 61 & $\begin{array}{l}\text { Charoenjit } \\
\text { et al. }\end{array}$ & [127] & 2012 & Thailand & THEOS & Medium & Local & Uni-temporal & $\begin{array}{c}\text { Biomass } \\
\text { and } \\
\text { Carbon }\end{array}$ & Tree Allometry & $\mathrm{Y}$ & $\mathrm{N}$ & $\mathrm{N}$ & Y & $\mathrm{Y}$ & $\mathrm{N}$ \\
\hline 62 & $\begin{array}{l}\text { Charoenjit } \\
\text { et al. }\end{array}$ & [128] & 2015 & Thailand & THEOS & Medium & Local & Uni-temporal & $\begin{array}{c}\text { Biomass } \\
\text { and } \\
\text { Carbon }\end{array}$ & Tree Allometry & Y & $\mathrm{N}$ & $\mathrm{Y}$ & $\mathrm{N}$ & $\mathrm{N}$ & $\mathrm{Y}$ \\
\hline 63 & $\begin{array}{l}\text { Yasen \& } \\
\text { Koedsin }\end{array}$ & [129] & 2015 & Thailand & Worlview-2 & Very High & Local & Uni-temporal & $\begin{array}{c}\text { Biomass } \\
\text { and } \\
\text { Carbon }\end{array}$ & Tree Allometry & Y & $\mathrm{N}$ & $\mathrm{N}$ & $\mathrm{N}$ & $\mathrm{N}$ & $\mathrm{Y}$ \\
\hline 64 & Yang et al. & [106] & 2016 & China & $\begin{array}{l}\text { IKONOS, } \\
\text { SPOT, } \\
\text { RapidEye, } \\
\text { Landsat }\end{array}$ & $\begin{array}{c}\text { Medium + } \\
\text { High + Very } \\
\text { High }\end{array}$ & Local & Multi-temporal & $\begin{array}{c}\text { Biomass } \\
\text { and } \\
\text { Carbon }\end{array}$ & Tree Allometry & Y & $\mathrm{N}$ & $\mathrm{N}$ & $\mathrm{N}$ & $\mathrm{N}$ & $\mathrm{Y}$ \\
\hline 66 & $\begin{array}{l}\text { Anurogo } \\
\text { et al. }\end{array}$ & [131] & 2018 & Indonesia & ASTER & Medium & Local & Uni-temporal & $\begin{array}{c}\text { Biomass } \\
\text { and } \\
\text { Carbon }\end{array}$ & Tree Allometry & Y & $\mathrm{N}$ & $\mathrm{N}$ & Y & $\mathrm{N}$ & $\mathrm{Y}$ \\
\hline 67 & $\begin{array}{c}\text { Pratama \& } \\
\text { Danoe- } \\
\text { doro }\end{array}$ & [132] & 2020 & Indonesia & Sentinel-2 & High & Local & Uni-temporal & $\begin{array}{c}\text { Biomass } \\
\text { and } \\
\text { Carbon }\end{array}$ & Tree Allometry & Y & $\mathrm{N}$ & $\mathrm{Y}$ & $\mathrm{N}$ & $\mathrm{N}$ & $\mathrm{Y}$ \\
\hline 68 & Chen et al. & [133] & 2020 & China & $\begin{array}{l}\text { Landsat 7, } \\
\text { Landsat 8, } \\
\text { Sentinel-2 }\end{array}$ & $\begin{array}{l}\text { Medium }+ \\
\text { High }\end{array}$ & Local & Uni-temporal & $\begin{array}{l}\text { Biomass } \\
\text { and } \\
\text { Carbon }\end{array}$ & Tree Allometry & $\mathrm{Y}$ & $\mathrm{N}$ & $\mathrm{N}$ & $\mathrm{N}$ & $\mathrm{N}$ & $\mathrm{Y}$ \\
\hline 69 & $\begin{array}{c}\text { Kaewplang } \\
\& \\
\text { Vaiphasa }\end{array}$ & {$[56]$} & 2014 & Thailand & EO-1 Hyperion & Medium & Local & Uni-temporal & $\begin{array}{l}\text { Leaf } \\
\text { Area } \\
\text { Index }\end{array}$ & Regression model & $\mathrm{Y}$ & $\mathrm{N}$ & $\mathrm{N}$ & $\mathrm{N}$ & $\mathrm{N}$ & $\mathrm{Y}$ \\
\hline 70 & Chen et al. & [33] & 2015 & China & $\mathrm{HJ}-1, \mathrm{ZY} 3$ & $\begin{array}{c}\text { Medium }+ \\
\text { High }\end{array}$ & Local & Multi-temporal & $\begin{array}{l}\text { Leaf } \\
\text { Area } \\
\text { Index } \\
\end{array}$ & Regression model & Y & $\mathrm{N}$ & $\mathrm{N}$ & $\mathrm{N}$ & $\mathrm{N}$ & $\mathrm{Y}$ \\
\hline 71 & $\begin{array}{l}\text { Koedsin \& } \\
\text { Yasen }\end{array}$ & [139] & 2016 & Thailand & WorldView-2 & Very High & Local & Uni-temporal & $\begin{array}{l}\text { Leaf } \\
\text { Area } \\
\text { Index }\end{array}$ & Regression model & $\mathrm{Y}$ & $\mathrm{N}$ & $\mathrm{N}$ & $\mathrm{Y}$ & $\mathrm{N}$ & $\mathrm{Y}$ \\
\hline 72 & $\begin{array}{l}\text { Ranganathet } \\
\text { al. }\end{array}$ & [143] & 2004 & India & IRS & Medium & Local & Multi-temporal & Disease & Satellite platform & Y & $\mathrm{N}$ & $\mathrm{N}$ & Y & $\mathrm{N}$ & $\mathrm{N}$ \\
\hline
\end{tabular}


Table A1. Cont.

\begin{tabular}{|c|c|c|c|c|c|c|c|c|c|c|c|c|c|c|c|c|}
\hline \multirow[b]{2}{*}{ No } & \multirow[b]{2}{*}{ Authors } & \multirow[b]{2}{*}{ Ref } & \multirow[b]{2}{*}{ Year } & \multirow[b]{2}{*}{ Country } & \multirow[b]{2}{*}{ Sensor } & \multirow[b]{2}{*}{$\begin{array}{c}\text { Sensor } \\
\text { Resolution }\end{array}$} & \multirow[b]{2}{*}{$\begin{array}{c}\text { Spatial } \\
\text { Extent }\end{array}$} & \multirow[b]{2}{*}{$\begin{array}{l}\text { Temporal } \\
\text { Scale }\end{array}$} & \multirow[b]{2}{*}{$\begin{array}{l}\text { Subject } \\
\text { Area }\end{array}$} & \multirow[b]{2}{*}{ Approach } & \multicolumn{3}{|c|}{ Reference Data } & \multicolumn{3}{|c|}{ Accuracy Method } \\
\hline & & & & & & & & & & & $\begin{array}{c}\text { Ground } \\
\text { Data }\end{array}$ & $\begin{array}{c}\text { High } \\
\text { Resolution } \\
\text { Image }\end{array}$ & Others & $\begin{array}{l}\text { Error } \\
\text { Matrix }\end{array}$ & Kappa & $\mathbf{R}^{2} / \mathrm{RMSE}$ \\
\hline 73 & $\begin{array}{l}\text { Pradeep } \\
\text { et al. }\end{array}$ & [15] & 2014 & India & IRS, MODIS & $\begin{array}{l}\text { Low }+ \\
\text { Medium }\end{array}$ & Local & Multi-temporal & Disease & Satellite platform & Y & $\mathrm{N}$ & $\mathrm{N}$ & Y & $\mathrm{N}$ & $\mathrm{N}$ \\
\hline 74 & $\begin{array}{l}\text { Mohd Ali } \\
\text { et al. }\end{array}$ & [54] & 2018 & Malaysia & Drone & Very High & Local & Uni-temporal & Disease & $\begin{array}{c}\text { Unmanned } \\
\text { Aerial Vehicle } \\
\text { (UAV) }\end{array}$ & Y & $\mathrm{N}$ & $\mathrm{N}$ & $\mathrm{N}$ & $\mathrm{N}$ & $\mathrm{N}$ \\
\hline
\end{tabular}




\section{References}

1. Sanjeeva Rao, P.; Saraswathyamma, C.K.; Sethuraj, M.R. Studies on the relationship between yield and meteorological parameters of para rubber tree (Hevea brasiliensis). Agric. For. Meteorol. 1998, 90, 235-245. [CrossRef]

2. Food and Agriculture Organization of the United Nations (FAO) FAOSTAT Statistical Database 2020. Available online: http: //www.fao.org/faostat/en/?\#data/QC (accessed on 11 November 2020).

3. Van Beilen, J.B.; Poirier, Y. Establishment of new crops for the production of natural rubber. Trends Biotechnol. 2007, 25, 522-529. [CrossRef]

4. Carr, M.K.V. The water relations of rubber (hevea brasiliensis): A review. Exp. Agric. 2012, 48, 176-193. [CrossRef]

5. Nath, A.J.; Brahma, B.; Das, A.K. Rubber Plantations and Carbon Management; Apple Academic Press: Palm Bay, FL, USA, 2019; ISBN 9780429659867.

6. Ahrends, A.; Hollingsworth, P.M.; Ziegler, A.D.; Fox, J.M.; Chen, H.; Su, Y.; Xu, J. Current trends of rubber plantation expansion may threaten biodiversity and livelihoods. Glob. Environ. Chang. 2015, 34, 48-58. [CrossRef]

7. Fox, J.; Castella, J.C. Expansion of rubber (Hevea brasiliensis) in Mainland Southeast Asia: What are the prospects for smallholders? J. Peasant Stud. 2013, 40, 155-170. [CrossRef]

8. Promme, P.; Kuwornu, J.K.M.; Jourdain, D.; Shivakoti, G.P.; Soni, P. Factors influencing rubber marketing by smallholder farmers in Thailand. Dev. Pract. 2017, 27, 865-879. [CrossRef]

9. Barlow, C.; Jayasuriya, S.K. Problems of Investment for Technological Advance: The Case of Indonesian Rubber Smallholders. J. Agric. Econ. 1984, 35, 85-95. [CrossRef]

10. Douangsavanh, L.; Noble, A.; Thammavong, B. Meeting Regional and Global Demands for Rubber: A Key to Poverty Alleviation in Lao PDR? The Sustainable Mekong Research Network (Sumernet): Bangkok, Thailand, 2008.

11. Manivong, R.; Cramb, R.A. Economics of Smallholder Rubber Production in Northern Laos. Agrofor. Syst. 2008, 74, 113. [CrossRef]

12. Viswanathan, P.K. Emerging smallholder rubber farming systems in India and Thailand: A comparative economic analysis. Asian, J. Agric. Dev. 2008, 5, 2.

13. Konyeha, S.; Imouokhome, F.A. Development of a Web Based Expert System for Rubber Crop Disease Diagnosis and Management. J. Sci. Res. 2018, 10, 239-248. [CrossRef]

14. Manju, M.J.; Benagi, V.I.; Shankarappa, T.H.; Vinod, K.K.; Kuruvilla Jacob, C.; Jacob, C.K. Major Diseases of Hevea brasiliensis in Rubber Growing Regions of South India. Environ. Ecol. 2015, 33, 1299-1302.

15. Pradeep, B.; Meti, S.; James, J. Satellite based remote sensing technique as a tool for real time monitoring of leaf retention in natural rubber plantations affected by abnormal leaf fall disease. Int. Arch. Photogramm. Remote Sens. Spat. Inf. Sci. - ISPRS Arch. 2014, XL-8, 885-889. [CrossRef]

16. Beilen, J.V.; Poirier, Y.; Orts, B. Alternative Sources of Natural Rubber; Outputs from the EPOBIO Project; CPL Press: Berks, UK, 2006; ISBN 9781872691084.

17. Wastie, R.L. Diseases of rubber and their control. PANS Pest Artic. News Summ. 1975, 21, 268-288. [CrossRef]

18. Suratman, M.N. Applicability of Landsat TM Data for Inventorying and Monitoring Rubber (Hevea Brasiliensis) Plantations in Selangor, Malaysia: Linkages to Policies. Ph.D. Thesis, The University of British Columbia, Vancouver, BC, Canada, 2003.

19. Mongkolsawat, C.; Putklang, W. Rubber Tree Expansion in Forest Reserve and Paddy Field Across the Greater Mekong SubRegion, Northeast Thailand Based on Remotely Sensed Imagery. In Proceedings of the The 33rd Asian Conference on Remote Sensing, Pattaya, Thailand, 26-30 November 2012; Volume 1, pp. 214-219.

20. Majumder, A.; Datta, S. Do Extensive Rubber Plantation Influences Local Environment? A Case Study from Tripura, Northeast India. Curr. World Environ. 2014, 9, 768-779. [CrossRef]

21. Mann, C.C. Addicted to Rubber. Science (80-. ) 2009, 325, 564-566. [CrossRef]

22. Qiu, J. Where the rubber meets the garden. Nature 2009, 457, 246-247. [CrossRef]

23. Roy, M.M.; Saha, S.; Roy, M.M. ECOLOGICAL IMPACT OF RUBBER PLANTATIONS: TRIPURA PERSPECTIVE RESEARCH ARTICLE ECOLOGICAL IMPACT OF RUBBER PLANTATIONS: TRIPURA PERSPECTIVE. Int. J. Curr. Res. 2014, 6, 10334-10340.

24. Ziegler, A.D.; Fox, J.M.; Xu, J. The Rubber Juggernaut. Science (80-. ) 2009, 324, 1024-1025. [CrossRef]

25. Fukatsu, T.; Nanseki, T. Monitoring system for farming operations with wearable devices utilized sensor networks. Sensors 2009, 9, 6171-6184. [CrossRef] [PubMed]

26. Mdemu, M.; Kissoly, L.; Bjornlund, H.; Kimaro, E.; Christen, E.W.; van Rooyen, A.; Stirzaker, R.; Ramshaw, P. The role of soil water monitoring tools and agricultural innovation platforms in improving food security and income of farmers in smallholder irrigation schemes in Tanzania. Int. J. Water Resour. Dev. 2020, 36, 1-23. [CrossRef]

27. Nguyen, T.T.; Hoang, T.D.; Pham, M.T.; Vu, T.T.; Nguyen, T.H.; Huynh, Q.T.; Jo, J. Monitoring agriculture areas with satellite images and deep learning. Appl. Soft Comput. J. 2020, 95, 106565. [CrossRef]

28. Wang, Y. Plantation Monitoring System Based on Internet of Things. In Proceedings of the 2013 IEEE International Conference on Green Computing and Communications and IEEE Internet of Things and IEEE Cyber, Physical and Social Computing, Beijing, China, 20-23 August 2013. [CrossRef] 
29. Dibs, H.; Idrees, M.O.M.O.; Alsalhin, G.B.A.G.B.A.; Bedawi, G.; Alsalhin, A.; Alsalhin, G.B.A.G.B.A. Hierarchical classification approach for mapping rubber tree growth using per-pixel and object-oriented classifiers with SPOT-5 imagery. Egypt. J. Remote Sens. Sp. Sci. 2017, 20, 21-30. [CrossRef]

30. Perumal, K.; Bhaskaran, R. Supervised Classification Performance of Multispectral Images. J. Comput. $2010,2,124-129$.

31. Gao, S.; Liu, X.; Bo, Y.; Shi, Z.; Zhou, H. Rubber identification based on blended high spatio-temporal resolution optical remote sensing data: A case study in Xishuangbanna. Remote Sens. 2019, 11, 496. [CrossRef]

32. Liu, X.; Feng, Z.; Jiang, L.; Li, P.; Liao, C.; Yang, Y.; You, Z. Rubber plantation and its relationship with topographical factors in the border region of China, Laos and Myanmar. J. Geogr. Sci. 2013, 23, 1019-1040. [CrossRef]

33. Chen, B.; Wu, Z.; Wang, J.; Dong, J.; Guan, L.; Chen, J.; Yang, K.; Xie, G.; Chen, J.; Chen, B.; et al. Spatio-temporal prediction of leaf area index of rubber plantation using HJ-1A/1B CCD images and recurrent neural network. ISPRS J. Photogramm. Remote Sens. 2015, 102, 148-160. [CrossRef]

34. Dauwalter, D.C.; Fesenmyer, K.A.; Bjork, R.; Leasure, D.R.; Wenger, S.J. Satellite and Airborne Remote Sensing Applications for Freshwater Fisheries. Fisheries 2017, 42, 526-537. [CrossRef]

35. Nguyen, M.D.; Baez-Villanueva, O.M.; Bui, D.D.; Nguyen, P.T.; Ribbe, L. Harmonization of landsat and sentinel 2 for crop monitoring in drought prone areas: Case studies of Ninh Thuan (Vietnam) and Bekaa (Lebanon). Remote Sens. 2020, 12, 281. [CrossRef]

36. Li, Z.; Fox, J.M. Mapping rubber tree growth in mainland Southeast Asia using time-series MODIS $250 \mathrm{~m}$ NDVI and statistical data. Appl. Geogr. 2012, 32, 420-432. [CrossRef]

37. Liu, X.; Zhiming, F.; Luguang, J.; Jinghua, Z. Rubber Plantations in Xishuangbanna: Remote Sensing Identification and Digital Mapping. Resour. Sci. 2014, 34, 1769-1780.

38. Rao, D.V.N.; Jose, A.I.; Rao, A.V.R.K. Spectral signature and temporal variation in spectral reflectance: Keys to identify rubber vegetation. In Proceedings of the International Symposium on Remote Sensing, Crete, Greece, 22-25 September 2003; Volume 4879, pp. 114-124.

39. Fan, H.; Fu, X.; Zhang, Z.; Wu, Q. Phenology-based vegetation index differencing for mapping of rubber plantations using landsat OLI data. Remote Sens. 2015, 7, 6041-6058. [CrossRef]

40. Association of Natural Rubber Producing Countries (ANRPC). Nat. Rubber Trends Stat. 2020, 12, 1-12.

41. Liberati, A.; Altman, D.G.; Tetzlaff, J.; Mulrow, C.; Gøtzsche, P.C.; John, P.A. The PRiSMA statement for reporting systematic reviews and meta-analyses of studies that evaluate healthcare interventions: Explanation and elaboration. Res. Methods Report. 2009. [CrossRef] [PubMed]

42. Koutsos, T.M.; Menexes, G.C.; Dordas, C.A. An efficient framework for conducting systematic literature reviews in agricultural sciences. Sci. Total Environ. 2019, 682, 106-117. [CrossRef]

43. Moher, D.; Liberati, A.; Tetzlaff, J.; Altman, D. Preferred reporting items for systematic reviews and meta-analyses: The PRISMA statement... Preferred Reporting Items for Systematic reviews and Meta-Analyses. BMJ Br. Med. J. 2012, 8, b2535. [CrossRef]

44. Pae, C. Why Systematic Review rather than Narrative Review? Korean Neuropsychiatr. Assoc. 2015, 417, 417-419. [CrossRef]

45. Tricco, A.C.; Lillie, E.; Zarin, W.; O’Brien, K.; Colquhoun, H.; Kastner, M.; Levac, D.; Ng, C.; Sharpe, J.P.; Wilson, K.; et al. A scoping review on the conduct and reporting of scoping reviews. BMC Med. Res. Methodol. 2016, 16, 1-10. [CrossRef]

46. Mortensen, M.L.; Adam, G.P.; Trikalinos, T.A.; Kraska, T.; Wallace, B.C. An exploration of crowdsourcing citation screening for systematic reviews. Res. Synth. Methods 2017, 8, 366-386. [CrossRef]

47. Frampton, G.K.; Livoreil, B.; Petrokofsky, G. Eligibility screening in evidence synthesis of environmental management topics. Environ. Evid. 2017, 6, 1-13. [CrossRef]

48. Choong, M.K.; Galgani, F.; Dunn, A.G.; Tsafnat, G. Automatic evidence retrieval for systematic reviews. J. Med. Internet Res. 2014, 16, e223. [CrossRef]

49. Suratman, M.N.; Bull, G.Q.; Leckie, D.G.; LeMay, V.; Marshall, P.L. Modelling attributes of Rubberwood (Hevea brasiliensis) stands using spectral radiance recorded by Landsat Thematic Mapper in Malaysia. In Proceedings of the IEEE International Geoscience and Remote Sensing Symposium, Toronto, ON, Canada, 24-28 June 2002; Volume 4, pp. $2087-2090$.

50. Zhu, Z.; Wulder, M.A.; Roy, D.P.; Woodcock, C.E.; Hansen, M.C.; Radeloff, V.C.; Healey, S.P.; Schaaf, C.; Hostert, P.; Strobl, P.; et al. Benefits of the free and open Landsat data policy. Remote Sens. Environ. 2019, 224, 382-385. [CrossRef]

51. Makkonen, T.; Williams, A.M. Border region studies: The structure of an 'offbeat' field of regional studies. Reg. Stud. Reg. Sci. 2016, 3, 355-367. [CrossRef]

52. Nair, K.P.P. Rubber (Hevea brasiliensis); Elsevier: London, UK, 2010; ISBN 9780123846778.

53. Xiao, C.; Li, P.; Feng, Z. How did deciduous rubber plantations expand spatially in China's Xishuangbanna Dai Autonomous Prefecture during 1991-2016? Photogramm. Eng. Remote Sensing 2019, 85, 687-697. [CrossRef]

54. Mohd Ali, H.; Rasib, A.W.; Abd Hamid, N.R.; Ghani, Z.A.; Mahsuri, I.; Mohd Yusoff, A.R.; Zainon, O.; Idris, K.M.; Dollah, R. Determination of rubber-tree clones leaf diseases spectral using Unmanned Aerial Vehicle compact sensor. IOP Conf. Ser. Earth Environ. Sci. 2018, 169. [CrossRef]

55. Kaewplang, S.; Srihanu, N. An Evaluation of EO-1 Hyperion Data for Estimating Age of Rubber Plantation. Mahasarakham Int. J. Eng. Technol. 2017, 3, 5-9.

56. Kaewplang, S.; Vaiphasa, C. An Evaluation of EO-1 Hyperion Data for Estimating Leaf Area Index of Rubber Plantation. Int. J. Geoinformatics 2014, 10(3), 13-21. 
57. Pensuk, A.; Shrestha, R.P. Effect of Paddy Area Conversion to Rubber Plantation on Rural Livelihoods: A Case Study of Phatthalung Watershed, Southern Thailand. GMSARN Int. J. 2008, 2, 185-190.

58. Han, P.; Chen, J.; Han, Y.; Yi, L.; Zhang, Y.; Jiang, X. Monitoring rubber plantation distribution on Hainan Island using Landsat OLI imagery. Int. J. Remote Sens. 2018, 39, 2189-2206. [CrossRef]

59. Abd Razak, J.A.M.; Shariff, A.R.; Ahmad, N.; Sameen, M.I. Mapping rubber trees based on phenological analysis of Landsat time series data-sets. Geocarto Int. 2018, 627-650. [CrossRef]

60. Min, S.; Huang, J.; Waibel, H.; Yang, X.; Cadisch, G. Rubber Boom, Land Use Change and the Implications for Carbon Balances in Xishuangbanna, Southwest China. Ecol. Econ. 2019, 156, 57-67. [CrossRef]

61. Chen, B.; Xiao, X.; Ye, H.; Ma, J.; Doughty, R.; Li, X.; Zhao, B.; Wu, Z.; Sun, R.; Dong, J.; et al. Mapping Forest and Their Spatial-Temporal Changes from 2007 to 2015 in Tropical Hainan Island by Integrating ALOS/ALOS-2 L-Band SAR and Landsat Optical Images. IEEE J. Sel. Top. Appl. Earth Obs. Remote Sens. 2018, 11, 852-867. [CrossRef]

62. Sun, Z.; Leinenkugel, P.; Guo, H.; Huang, C.; Kuenzer, C. Extracting distribution and expansion of rubber plantations from Landsat imagery using the C5.0 decision tree method. J. Appl. Remote Sens. 2017. [CrossRef]

63. Chakraborty, K.; Sudhakar, S.; Sarma, K.K.K.; Raju, P.L.N.N.; Das, A.K.A.K.; Sudhakar, S.; Chakraborty, K.; Sarma, K.K.K.; Sudhakar, S.; Sarma, K.K.K.; et al. Recognizing the rapid expansion of rubber plantation - A threat to native forest in parts of northeast India. Curr. Sci. 2018, 114, 207-213. [CrossRef]

64. Suratman, M.N.N. Rubber acreage change detection using landsat TM: Linkages to policies. ASPRS Annu. Conf. 2007 Identifying Geospatial Solut. 2007, 2, 698-709.

65. Meti, S.; Rao, D.V.K.N.; Nair, N.U.U.; Jacob, J. Distribution of natural rubber cultivation in relation to soil and landscape attributes in India. In Proceedings of the 29th Asian Conference on Remote Sensing 2008, ACRS 2008, Colombo, Sri Lanka, 10-14 November 2008; Volume 1, pp. 7-16.

66. Lillesand, T.M.; Kiefer, R.W.; Jonathan, W.C. Remote Sensing and Image Interpretation, 7th ed.; John Wiley \& Sons, Inc.: New York City, NY, USA, 2015; ISBN 9781118919453.

67. Suratman, M.N.; Lemay, V.M.; Bull, G.Q.; Donald, G.; Walsworth, N.; Marshall, P.L. Logistic regression modelling of thematic mapper data for rubber ( Hevea brasiliensis ) area mapping. Sci. Lett. 2005, 2, 79-85.

68. Li, Z.; Fox, J.M. Integrating Mahalanobis typicalities with a neural network for rubber distribution mapping. Remote Sens. Lett. 2011, 2, 157-166. [CrossRef]

69. Shidiq, I.P.A.; Ismail, M.H.; Kamarudin, N. Initial results of the spatial distribution of rubber trees in Peninsular Malaysia using remotely sensed data for biomass estimate. IOP Conf. Ser. Earth Environ. Sci. 2014, 18. [CrossRef]

70. Shidiq, I.P.A.; Ismail, M.H.; Ramli, M.F.; Kamarudin, N. Combination of ALOS PALSAR and Landsat 5 imagery for rubber tree mapping. Malaysian For. 2017, 80, 55-72.

71. Zhang, C.; Huang, C.; Li, H.; Liu, Q.; Li, J.; Bridhikitti, A.; Liu, G. Effect of Textural Features in Remote Sensed Data on Rubber Plantation Extraction at Di ff erent Levels of Spatial Resolution. Forests 2020, 11, 399. [CrossRef]

72. Dong, J.; Xiao, X.; Chen, B.; Torbick, N.; Jin, C.; Zhang, G.; Biradar, C. Mapping deciduous rubber plantations through integration of PALSAR and multi-temporal Landsat imagery. Remote Sens. Environ. 2013, 134, 392-402. [CrossRef]

73. Dai, S.P.; Luo, H.X.; Fang, J.H.; Cao, J.H.; Li, H.L.; Li, M.F.; Wang, L.L.; Luo, W. Object-oriented classification of rubber plantations from Landsat satellite imagery. In Proceedings of the 2014 The 3rd International Conference on Agro-Geoinformatics, Agro-Geoinformatics, Beijing, China, 11-14 August 2014.

74. Li, P.; Zhang, J.; Feng, Z. Mapping rubber tree plantations using a Landsat-based phenological algorithm in Xishuangbanna, southwest China. Remote Sens. Lett. 2015, 6, 49-58. [CrossRef]

75. Pradeep, B.; Jacob, J.; Anand, S.S.S.; Shebin, S.M.M.; Meti, S.; Annamalainathan, K. Inventory of Rubber Plantations and Identification of Potential Areas For Its Cultivation In Assam Using High Resolution IRS Data. In Proceedings of the 38th Asian Conference on Remote Sensing, Asian Association on Remote Sensing (AARS), New Delhi, India, 23-27 October 2017; pp. 1977-1985.

76. Zhai, D.; Dong, J.; Cadisch, G.; Wang, M.; Kou, W.; Xu, J.; Xiao, X.; Abbas, S. Comparison of pixel- and object-based approaches in phenology-based rubber plantation mapping in fragmented landscapes. Remote Sens. 2018, 10, 44. [CrossRef]

77. Xiao, C.; Li, P.; Feng, Z. A renormalized modified normalized burn ratio (RMNBR) index for detecting mature rubber plantations with Landsat-8 OLI in Xishuangbanna, China. Remote Sens. Lett. 2019, 10, 214-223. [CrossRef]

78. Xiao, C.; Li, P.; Feng, Z.; Lin, Y.; You, Z.; Yang, Y. Mapping rubber plantations in Xishuangbanna, southwest China based on the re-normalization of two Landsat-based vegetation-moisture indices and meteorological data. Geocarto Int. 2019, 0, 1-15. [CrossRef]

79. Mohd Hazir, M.H.; Tuan Muda, T.M. The viability of remote sensing for extracting rubber smallholding information: A case study in Malaysia. Egypt. J. Remote Sens. Sp. Sci. 2020, 23, 35-47. [CrossRef]

80. Xiao, C.; Li, P.; Feng, Z.; Liu, Y.; Zhang, X. Sentinel-2 red-edge spectral indices (RESI) suitability for mapping rubber boom in Luang Namtha Province, northern Lao PDR. Int. J. Appl. Earth Obs. Geoinf. 2020, 93, 102176. [CrossRef]

81. Xiao, C.; Li, P.; Feng, Z.; You, Z.; Jiang, L.; Boudmyxay, K. Is the phenology-based algorithm for mapping deciduous rubber plantations applicable in an emerging region of northern Laos? Adv. Space Res. 2020, 65, 446-457. [CrossRef]

82. Mishra, S.; Shrivastava, P.; Dhurvey, P. Change Detection Techniques in Remote Sensing: A Review. Int. J. Wirel. Mob. Commun Ind. Syst. 2017, 4, 1-8. [CrossRef]

83. Al-doski, J.; Mansor, S.; Shafri, H. Change Detection Process and Techniques. Civ. Environ. Res. 2013, 3, 37-46. 
84. Xiao, C.; Li, P.; Feng, Z. Monitoring annual dynamics of mature rubber plantations in Xishuangbanna during 1987-2018 using Landsat time series data: A multiple normalization approach. Int. J. Appl. Earth Obs. Geoinf. 2019, 77, 30-41. [CrossRef]

85. Chen, H.; Yi, Z.F.; Schmidt-Vogt, D.; Ahrends, A.; Beckschäfer, P.; Kleinn, C.; Ranjitkar, S.; Xu, J. Pushing the limits: The pattern and dynamics of rubber monoculture expansion in Xishuangbanna, SW China. PLoS ONE 2016, 1-15. [CrossRef] [PubMed]

86. Putklang, W.; Maneechot, S.; Mongkolsawat, C. Assessing Thaichote satellite data in support of mapping rubber tree plantation in Northeast Thailand. In Proceedings of the 33rd Asian Conference on Remote Sensing, Pattaya, Thailand, 26-30 November 2012; Volume 3, pp. 2269-2275.

87. Grogan, K.; Pflugmacher, D.; Hostert, P.; Mertz, O.; Fensholt, R. Unravelling the link between global rubber price and tropical deforestation in Cambodia. Nat. Plants 2019, 5, 47-53. [CrossRef] [PubMed]

88. Grogan, K.; Pflugmacher, D.; Hostert, P.; Kennedy, R.; Fensholt, R. Cross-border forest disturbance and the role of natural rubber in mainland Southeast Asia using annual Landsat time series. Remote Sens. Environ. 2015. [CrossRef]

89. Liu, W.; Hu, H.; Ma, Y.; Li, H. Environmental and Socioeconomic Impacts of Increasing Rubber Plantations in Menglun Township, Southwest China. Mt. Res. Dev. 2006, 26, 245-253. [CrossRef]

90. Bafouet, B.; Koula, J.; Kouakou Bob, K.; Wandan, E.N. Spatial projection of dynamic modeling system: Exploration of Rubber tree plantation and the consequences of REDD+ for the populations of Toumodi in Côte d'Ivoire. J. Biodivers. Environ. Sci. J. Bio. Environ. Sci 2017, 11, 7-20.

91. Mahmoud, A.; Elbialy, S.; Pradhan, B.; Buchroithner, M. Field-based landcover classification using TerraSAR-X texture analysis. Adv. Space Res. 2011, 48, 799-805. [CrossRef]

92. Soergel, U. Radar Remote Sensing of Urban Areas; Springer: Berlin, Germany, 2010; Volume 15, ISBN 9789048137503.

93. Twisa, S.; Buchroithner, M.F. Land-use and land-cover (LULC) change detection in Wami river basin, Tanzania. Land 2019, 8, 136. [CrossRef]

94. Li, H.; Aide, T.M.; Ma, Y.; Liu, W.; Cao, M. Demand for rubber is causing the loss of high diversity rain forest in SW China. Biodivers. Conserv. 2007, 16, 1731-1745. [CrossRef]

95. Zhai, D.L.; Cannon, C.H.; Slik, J.F.; Zhang, C.P.; Dai, Z.C. Rubber and pulp plantations represent a double threat to Hainan's natural tropical forests. J. Environ. Manage. 2012, 96, 64-73. [CrossRef]

96. Özdoğan, M.; Baird, I.G.I.; Dwyer, M.B.M. The Role of Remote Sensing for Understanding Large-Scale Rubber Concession Expansion in Southern Laos. Land 2018, 7, 55. [CrossRef]

97. Liu, X.; Jiang, L.; Feng, Z.; Li, P. Rubber plantation expansion related land use change along the Laos-China Border Region. Sustainability 2016, 8, 1011. [CrossRef]

98. Kou, W.; Dong, J.; Xiao, X.; Hernandez, A.J.; Qin, Y.; Zhang, G.; Chen, B.; Lu, N.; Doughty, R. Expansion dynamics of deciduous rubber plantations in Xishuangbanna, China during 2000-2010. GIScience Remote Sens. 2018, 55, 905-925. [CrossRef]

99. Ye, S.; Rogan, J.; Sangermano, F. Monitoring rubber plantation expansion using Landsat data time series and a Shapelet-based approach. ISPRS J. Photogramm. Remote Sens. 2018, 136, 134-143. [CrossRef]

100. Vadjunec, J.M.; Gomes, C.V.A.; Ludewigs, T. Land-use/land-cover change among rubber tappers in the Chico Mendes Extractive Reserve, Acre, Brazil. J. Land Use Sci. 2009, 4, 249-274. [CrossRef]

101. Ekadinata, A.; Vincent, G. Rubber agroforests in a changing landscape: Analysis of land use/cover trajectories in bungo district, indonesia. For. Trees Livelihoods 2011, 20, 3-14. [CrossRef]

102. Joshi, L.; Pasha, R. Rubber agroforestry and PES for preservation of biodiversity in Bungo district, Sumatra. In Payments for Ecosystem Services and Food Security; FAO: Rome, Italy, 2011; pp. 114-135. ISBN 978-92-5-106796-3.

103. Phompila, C.; Lewis, M.; Clarke, K.; Ostendorf, B. Monitoring expansion of plantations in Lao tropical forests using Landsat time series. In Proceedings of the SPIE Asia-Pacific Remote Sensing, Beijing, China, 13-17 October 2014; Volume 9260, pp. 1-11.

104. Clément-Demange, A.; Garcia, D.; Le Guen, V.; Pujade-Renaud, V.; Montoro, P.; Seguin, M. Rubber Genetics and Breeding at Cirad-France Country Report of Activities from 2007 to 2011 (AGAP Research Unit); IRRDB Breeding Group Workshop: Bahia, Brazil, 2011; Volume 2011.

105. Cotter, M.; Asch, F.; Hilger, T.; Rajaona, A.; Schappert, A.; Stuerz, S.; Yang, X. Measuring leaf area index in rubber plantations-A challenge. Ecol. Indic. 2017, 82, 357-366. [CrossRef]

106. Yang, X.; Blagodatsky, S.; Lippe, M.; Liu, F.; Hammond, J.; Xu, J.; Cadisch, G. Land-use change impact on time-averaged carbon balances: Rubber expansion and reforestation in a biosphere reserve, South-West China. For. Ecol. Manag. 2016, 372, 149-163. [CrossRef]

107. Chen, B.; Xiao, X.; Wu, Z.; Yun, T.; Kou, W.; Ye, H.; Lin, Q.; Doughty, R.; Dong, J.; Ma, J.; et al. Identifying establishment year and pre-conversion land cover of rubber plantations on Hainan Island, China using Landsat data during 1987-2015. Remote Sens. 2018, 10, 240. [CrossRef]

108. Suratman, M.N.; Bull, G.Q.; Leckie, D.G.; Lemay, V.M.; Marshall, P.L.; Mispan, M.R. Prediction models for estimating the area, volume, and age of rubber (Hevea brasiliensis) plantations in Malaysia using Landsat TM data. Int. For. Rev. 2004, 6,1-12. [CrossRef]

109. Shidiq, I.P.A.; Ismail, M.H. Stand age model for mapping spatial distribution of rubber tree using remotely sensed data in Kedah, Malaysia. J. Teknol. 2016, 78, 239-244. [CrossRef]

110. Chen, B.; Cao, J.; Wang, J.; Wu, Z.; Tao, Z.; Chen, J.; Yang, C.; Xie, G. Estimation of rubber stand age in typhoon and chilling injury afflicted area with Landsat TM data: A case study in Hainan Island, China. For. Ecol. Manag. 2012, 274, 222-230. [CrossRef] 
111. Chen, G.; Thill, J.-C.J.C.; Anantsuksomsri, S.; Tontisirin, N.; Tao, R. Stand age estimation of rubber (Hevea brasiliensis) plantations using an integrated pixel- and object-based tree growth model and annual Landsat time series. ISPRS J. Photogramm. Remote Sens. 2018, 144, 94-104. [CrossRef]

112. Mongkolsawat, C.; Putklang, W.; Charat, M.; Wasana, P. An approach for estimating area of rubber plantation: Integrating satellite and physical data over the Northeast Thailand. In Proceedings of the 31st Asian Conference on Remote Sensing 2010, ACRS 2010, Hanoi, Vietnam, 1-5 November 2010; Volume 2, pp. 1228-1234.

113. Li, Z.; Fox, J.M. Rubber Tree Distribution Mapping in Northeast Thailand. Int. J. Geosci. 2011, 02, 573-584. [CrossRef]

114. Koedsin, W.; Huete, A. Mapping rubber tree stand age using pléiades satellite imagery: A case study in Thalang District, Phuket, Thailand. Eng. J. 2015, 19, 45-56. [CrossRef]

115. Dibs, H.; Mansor, S. Mapping Rubber Tree Growth by Spectral Angle Mapper Spectral-based and Pixel-based Classification Using SPOT-5 Image. In Proceedings of the 36th Asian Conference on Remote Sensing 2015, ACRS 2015, Manila, Philippines, 19-23 October 2015.

116. Somching, N.; Wongsai, S.; Wongsai, N.; Koedsin, W. Using machine learning algorithm and landsat time series to identify establishment year of para rubber plantations: A case study in Thalang district, Phuket Island, Thailand. Int. J. Remote Sens. 2020, 41, 9075-9100. [CrossRef]

117. Beckschäfer, P. Obtaining rubber plantation age information from very dense Landsat TM \& ETM + time series data and pixel-based image compositing. Remote Sens. Environ. 2017, 196, 89-100. [CrossRef]

118. Xiao, C.; Li, P.; Feng, Z.; Liu, X. An updated delineation of stand ages of deciduous rubber plantations during 1987-2018 using Landsat-derived bi-temporal thresholds method in an anti-chronological strategy. Int. J. Appl. Earth Obs. Geoinf. 2019, 76, 40-50. [CrossRef]

119. Kou, W.; Xiao, X.; Dong, J.; Gan, S.; Zhai, D.; Zhang, G.; Qin, Y.; Li, L. Mapping deciduous rubber plantation areas and stand ages with PALSAR and landsat images. Remote Sens. 2015, 7, 1048-1073. [CrossRef]

120. Blagodatsky, S.; Xu, J.; Cadisch, G. Carbon balance of rubber (Hevea brasiliensis) plantations: A review of uncertainties at plot, landscape and production level. Agric. Ecosyst. Environ. 2016, 221, 8-19. [CrossRef]

121. Brahma, B.; Nath, A.J.; Das, A.K. Managing rubber plantations for advancing climate change mitigation strategy. Curr. Sci. 2016, 110, 2015-2019. [CrossRef]

122. Min, S.; Wang, X.; Jin, S.; Waibel, H.; Huang, J. Climate change and farmers' perceptions: Impact on rubber farming in the upper Mekong region. Clim. Change 2020. [CrossRef]

123. Fox, J.; Castella, J.-C.; Ziegler, A.D.; Westley, S.B. Expansion of Rubber Mono-cropping and its Implications for the Resilience of Ecosystems in the Face of Climate Change in Montane Mainland Southeast Asia. Glob. Environ. Res. 2014, 18, 145-150.

124. Verchot, L.V.; Van Noordwijk, M.; Kandji, S.; Tomich, T.; Ong, C.; Albrecht, A.; Mackensen, J.; Bantilan, C.; Anupama, K.V.; Palm, C. Climate change: Linking adaptation and mitigation through agroforestry. Mitig. Adapt. Strateg. Glob. Chang. 2007, 12, 901-918. [CrossRef]

125. Shi, L.; Liu, S. Methods of Estimating Forest Biomass: A Review. Biomass Vol. Estim. Valorization Energy 2017. [CrossRef]

126. Kumar, L.; Mutanga, O. Remote sensing of above-ground biomass. Remote Sens. 2017, 9, 935. [CrossRef]

127. Charoenjit, K.; Zuddas, P.; Allemand, P. Estimation of carbon storage in Para rubber plantations using THAICHOTE and object based image analysis: Eastern Thailand. In Proceedings of the Asian Conference on Remote Sensing 2012 (ACRS 2012), Pattaya, Thailand, 26-30 November 2012; Volume 3, pp. 2020-2029.

128. Charoenjit, K.; Zuddas, P.; Allemand, P.; Pattanakiat, S.; Pachana, K.; Pattanakiat, S. Estimation of biomass and carbon stock in Para rubber plantations using object-based classification from Thaichote satellite data in Eastern Thailand. J. Appl. Remote Sens. 2015, 9, 096072. [CrossRef]

129. Yasen, K.; Koedsin, W. Estimating Aboveground Biomass of Rubber Tree Using Remote Sensing in Phuket Province, Thailand. J. Med. Bioeng. 2015, 4, 451-456. [CrossRef]

130. Anurogo, W.; Lubis, M.Z.; Mufida, M.K. Modified Soil-Adjusted Vegetation Index In Multispectral Remote Sensing Data for Estimating Tree Canopy Cover Density at Rubber Plantation. J. Geosci. Eng. Environ. Technol. 2018, 3, 15-21. [CrossRef]

131. Anurogo, W.; Lubis, M.Z.; Sari, L.R.; Mufida, M.K.; Prihantarto, W.J. Satellite-based Estimation of above Ground Carbon Stock Estimation for Rubber Plantation in Tembir Salatiga Central Java. In Proceedings of the 4th International Conference on Science and Technology, ICST 2018, Yogyakarta, Indonesia, 7-8 August 2018.

132. Pratama, L.D.Y.; Danoedoro, P. Above-ground carbon stock estimates of rubber (hevea brasiliensis) using Sentinel 2A imagery: A case study in rubber plantation of PTPN IX Kebun Getas and Kebun Ngobo, Semarang Regency. IOP Conf. Ser. Earth Environ. Sci. 2020, 500, 1-9. [CrossRef]

133. Chen, B.; Yun, T.; Ma, J.; Kou, W.; Li, H.; Yang, C.; Xiao, X.; Zhang, X.; Sun, R.; Xie, G.; et al. High-Precision Stand Age Data Facilitate the Estimation of Rubber Plantation Biomass: A Case Study of Hainan Island, China. Remote Sens. 2020, 12, 3853. [CrossRef]

134. Muukkonen, P.; Heiskanen, J. Estimating biomass for boreal forests using ASTER satellite data combined with standwise forest inventory data. Remote Sens. Environ. 2005, 99, 434-447. [CrossRef]

135. Xie, Y.; Sha, Z.; Yu, M.; Bai, Y.; Zhang, L. A comparison of two models with Landsat data for estimating above ground grassland biomass in Inner Mongolia, China. Ecol. Model. 2009, 220, 1810-1818. [CrossRef] 
136. Vicente-Serrano, S.M.; Pérez-Cabello, F.; Lasanta, T. Assessment of radiometric correction techniques in analyzing vegetation variability and change using time series of Landsat images. Remote Sens. Environ. 2008, 112, 3916-3934. [CrossRef]

137. Spanner, M.; Johnson, L.; Miller, J.; Mccreight, R.; Applications, S.E.; May, N.; Gong, P. Remote Sensing of Seasonal Leaf Area Index Across the Oregon Transect Freemantle. Ecol. Appl. 1994, 4, 258-271. Available online: http://www.jstor.org/stable/1941932 (accessed on 27 June 2016). [CrossRef]

138. Sprintsin, M.; Cohen, S.; Maseyk, K.; Rotenberg, E.; Grünzweig, J.; Karnieli, A.; Berliner, P.; Yakir, D. Long term and seasonal courses of leaf area index in a semi-arid forest plantation. Agric. For. Meteorol. 2011, 151, 565-574. [CrossRef]

139. Koedsin, W.; Yasen, K. Estimating Leaf Area Index of Rubber Tree Plantation Using Worldview-2 Imagery. J. Life Sci. Technol. 2016. [CrossRef]

140. Fang, H.; Baret, F.; Plummer, S.; Schaepman-Strub, G. An Overview of Global Leaf Area Index (LAI): Methods, Products, Validation, and Applications. Rev. Geophys. 2019, 57, 739-799. [CrossRef]

141. Jain, S.M.; Priyadarshan, P.M. Breeding Plantation Tree Crops: Tropical Species; Springer Science+Business Media: Berlin, Germany, 2009; ISBN 9780387712031.

142. Priyadarshan, P.M. Biology of Hevea Rubber; Springer International Publishing AG: Berlin, Germany, 2017 ; ISBN 9783319545066.

143. Ranganath, B.K.K.; Pradeep, N.; Manjula, V.B.B.; Gowda, B.; Rajanna, M.D.D.; Shettigar, D.; Rao, P.P.N.P.N. Detection of diseased rubber plantations using satellite remote sensing. J. Indian Soc. Remote Sens. 2004, 32, 49-58. [CrossRef]

144. Verheye, W. Soils, Plant Growth and Crop Production-Volume III. Encycl. Life Support Syst. 2010, 1-20. [CrossRef]

145. Langenberger, G.; Cadisch, G.; Martin, K.; Min, S.; Waibel, H. Rubber intercropping: A viable concept for the 21st century? Agrofor. Syst. 2016, 577-596. [CrossRef]

146. Abdulla, I.; Arshad, F.M. Exploring relationships between rubber productivity and R \& D in Malaysia. Outlook Agric. 2017. [CrossRef]

147. Somboonsuke, B.; Shivakoti, G.P. Small holders of rubber-based farming systems in Songkhla Province Thailand: Problems and potential solutions. Kasetsart J. Soc. Sci. 2001, 97, 79-97.

148. Weiss, M.; Jacob, F.; Duveiller, G. Remote sensing for agricultural applications: A meta-review. Remote Sens. Environ. 2020, 236, 111402. [CrossRef]

149. Pavlovic, D.; Nikolic, B.; Djurovic, S.; Waisi, H.; Andjelkovic, A.; Marisavljevic, D. Chlorophyll as a measure of plant health: Agroecological aspects. Pestic. $i$ Fitomedicina 2014, 29, 21-34. [CrossRef]

150. Ghamisi, P.; Rasti, B.; Yokoya, N.; Gloaguen, R.; Wang, Q.; Höfle, B.; Bruzzone, L.; Bovolo, F.; Chi, M.; Anders, K.; et al. Multisource and Multitemporal Data Fusion in Remote Sensing. arXiv 2018, arXiv:1812.08287.

151. Ranchin, T.; Paris, M. De Data Fusion in Remote Sensing and Improvement of the Spatial Resolution of Satellite Images. In Multisensor Fusion; Springer: Dordrecht, The Netherlands, 2002; pp. 633-656. ISBN 9781402007231.

152. Zhang, J. Multi-source remote sensing data fusion: Status and trends. Int. J. Image Data Fusion 2010, 1, 5-24. [CrossRef]

153. Gao, F.; Hilker, T.; Zhu, X.; Anderson, M.; Masek, J.; Wang, P.; Yang, Y. Fusing Landsat and MODIS Data for Vegetation Monitoring. IEEE Geosci. Remote Sens. Mag. 2015, 3, 47-60. [CrossRef]

154. Jia, D.; Song, C.; Cheng, C.; Shen, S.; Ning, L.; Hui, C. A novel deep learning-based spatiotemporal fusion method for combining satellite images with different resolutions using a two-stream convolutional neural network. Remote Sens. 2020, 12, 698. [CrossRef]

155. Zhu, X.; Helmer, E.H.; Gao, F.; Liu, D.; Chen, J.; Lefsky, M.A. A flexible spatiotemporal method for fusing satellite images with different resolutions. Remote Sens. Environ. 2016, 172, 165-177. [CrossRef]

156. Dong, J.; Metternicht, G.; Hostert, P.; Fensholt, R.; Chowdhury, R.R. Remote sensing and geospatial technologies in support of a normative land system science: Status and prospects. Curr. Opin. Environ. Sustain. 2019, 38, 44-52. [CrossRef]

157. Gorelick, N.; Hancher, M.; Dixon, M.; Ilyushchenko, S.; Thau, D.; Moore, R. Google Earth Engine: Planetary-scale geospatial analysis for everyone. Remote Sens. Environ. 2017, 202, 18-27. [CrossRef]

158. Moshou, D.; Gravalos, I.; Kateris, D.; Bravo, C.; Oberti, R.; West, J.S.; Ramon, H. Multisensor fusion of remote sensing data for crop disease detection. In Geospatial Techniques for Managing Environmental Resources; Springer Science \& Business Media: Berlin, Germany, 2012; ISBN 9789400718586. 